\title{
ASCENSO Y DECLIVE DE LA POLICÍA DE NARCÓTICOS DEL DEPARTAMENTO DE SALUBRIDAD PÚBLICA EN MÉXICO (1917-1960)
}

\author{
Carlos A. Pérez Ricart \\ Centro de Investigación y Docencia Económicas
}

Nidia A. Olvera Hernández
Instituto Mora

E ${ }_{\text {rato artículo rastrea la emergencia, ascenso y declive del apa- }}^{\text {sal encargado del control de drogas dentro del }}$ Departamento de Salubridad Pública (DSP, después Secretaría de Salubridad y Asistencia, sSA) entre 1917 y 1960. El artículo examina los orígenes y cambios organizacionales del aparato policial de Narcóticos, las prácticas de sus agentes en el ejercicio de la regulación de las leyes de la época y las razones de su lenta -pero progresiva- pérdida de importancia hacia inicios de la década de los cuarenta en favor de la Policía Judicial, anclada en la Procuraduría General de la República (PGR), el Ejército, así como de otras policías locales. Este artículo presenta -a partir de un estudio de caso- la forma en la que el Estado mexicano modificó gradualmente su interpretación del problema de las drogas, mismo que pasa de estar asociado a temas relativos a la

Fecha de recepción: 18 de septiembre de 2019

Fecha de aceptación: 7 de febrero de 2020 
salud pública a ser codificado en términos de seguridad. Como se demuestra en el artículo, se trató de un proceso lento y complejo que no debe verse de una forma binaria sino progresiva.

El artículo dialoga con tres diferentes áreas de investigación. En primer lugar, participa en el esfuerzo más amplio por documentar los caminos institucionales de las policías de México en la primera mitad del siglo xx. Se trata de una agenda en ebullición y que ya cuenta con un corpus importante de trabajos. ${ }^{1}$ En segundo lugar, el artículo participa en la cada vez más rica y extensa bibliografía sobre el estudio histórico del control de drogas en México. ${ }^{2}$ Finalmente, al rastrear los cambios organizativos de la policía antinarcóticos, este artículo también examina algunos de los cambios y continuidades en la historia del comercio de drogas en México, tercer campo de investigación al que este artículo interpela. ${ }^{3}$

La principal base documental del artículo es el Archivo Histórico de la Secretaría de Salud (AHSSA), sitio en el que se conservan los informes de labores de la Policía de Narcóticos del DSP, así como los registros de su personal. La revisión de los fondos del AHSSA estuvo acompañada del examen de otra media docena de archivos en México y Estados Unidos, incluyendo el Archivo General de la Nación (AGN), el Archivo Histórico

1 Véase Dávalos, Hernández Franyuti y Pulido Esteva (eds.), Orden, policía y seguridad; Pulido Esteva, "Trabajo, clase y prácticas policiales", pp. 667-711; Pulido Esteva, "Gendarmes, inspectores y comisarios”, pp. 37-58; SPECKMAN, "En la inmensa urbe y el laberinto de los archivos”, pp. 111-152; Pulido Esteva, "El caso Quintana”, pp. 312-329; Piccato, A History of Infamy; Pérez Ricart, "El papel de la DeA", pp. 5-48; Piccato, City of Suspects: Crime in Mexico City; Olvera Hernández, "Policías, toxicómanos y traficantes"; Schievenini, "La criminalización del consumo de marihuana".

2 Véase Pérez Montfort, Yerba, goma y polvo; Pérez Montfort, Tolerancia y probibición; CAmpos, Home Grown; Enciso, Nuestra historia narcótica; SMITH, "The Rise and Fall of Narcopopulism", pp. 125-165.

3 Astorga, Drogas sin fronteras y "Traficantes de drogas, políticos y policías", pp. 167-193; SмIтH, “The Rise and Fall of Narcopopulism”, pp. 125-165. 
de la Ciudad de México (AHCM), el Archivo Histórico de la Suprema Corte de Justicia (AHSCJ), así como el National Archives and Record Administration (NARA) en su sede de Maryland, Estados Unidos, la Biblioteca Emilio Portes Gil de la Procuraduría General de la República y la Biblioteca de la Secretaría de la Defensa Nacional. Además, se revisaron revistas y periódicos de la época depositados en el Fondo Contemporáneo de la Hemeroteca Nacional de México.

Las limitaciones de un texto de este carácter son múltiples. El más obvio tiene que ver con el carácter fragmentario e incompleto de los archivos históricos de los archivos policiales en México. Alzan la voz para subrayar el carácter oficial de sus enunciados, pero callan todo lo que se teje en las zonas grises de su accionar. Para utilizar las descripciones de quienes se han infiltrado en la documentación de papeles policiacos en México, podemos decir que estos son "temperamentales" y guardan "zonas de silencio". ${ }^{5}$ Lo escrito en los archivos policiales es siempre una combinación entre el resultado de fobias personales, reflejos del zeitgeist dominante y espejos de guerrillas burocráticas. Invariablemente todos ocultan e ignoran cosas.

Los archivos policiales que tratan temas de drogas nos dejan ver todo aquello que Paul Gootenberg identifica como la "cosmología oficial de lo ilícito"; 6 son ventanas desde las que es posible observar el tipo de conversación que el Estado tiene consigo mismo: un "diálogo en el que el Estado se despoja de muchas de sus categorías, suposiciones y premisas de sus comunicados públicos". 7 El y la historiadora deberán no reproducir el discurso oficial ni creer que lo que los documentos transmiten empatan con una realidad siempre más compleja (y casi siempre más cruda).

${ }^{4}$ Aguayo, La charola: una historia, pp. 24-25.

5 Astorga, Drogas sin fronteras, p. 12.

6 Gootenberg, "Talking about the Flow", p. 37.

7 Boyce, Banister y Slack, "You and What Army?”, p. 6. 
Otro límite del artículo es su atención casi exclusiva a una sola institución: la Policía de Narcóticos del Departamento de Salubridad Pública en México. Si bien se trata del objeto de estudio de este texto, es preciso señalar que no se trató de la única institución estatal que intervino directamente en el ejercicio de la política policial antinarcóticos. Otras instituciones, como la Secretaría de Gobernación, primero mediante agentes del Departamento Confidencial (1920-1934), posteriormente por medio de inspectores de la Oficina de Investigaciones Políticas y Sociales (1941-1947) y después mediante agentes de la Dirección Federal de Seguridad (1947-1985), también participaron en la investigación y persecución de traficantes de drogas. ${ }^{8}$ Su análisis, sin embargo, rebasa las ambiciones de este trabajo.

Los documentos utilizados para este artículo presentan evidencia para desarrollar los siguientes argumentos: 1) La Policía de Narcóticos -o Servicio de Narcóticos, como se le llamó en sus primeros años- nunca tuvo claridad sobre los límites y alcances de sus funciones. Aunque nominalmente su función se circunscribía a la inspección y vigilancia del ordenamiento legal, en la práctica ejerció facultades persecutorias y sancionadoras que se mezclaban -y entraban en conflicto- con las atribuciones de la Policía Judicial, los agentes del Ministerio Público y otras corporaciones policiacas locales; 2) Hacia mediados de los años cuarenta, la Policía de Narcóticos del DSP era una institución incapaz de hacer frente a las presiones desplegadas desde Estados Unidos que exigían un servicio profesional, de corte policial y dedicado enteramente a las tareas antinarcóticos; estar anclada a una institución de salud parecía un anacronismo

${ }^{8}$ En el fondo Investigaciones Politicas y Sociales del AGN existen múltiples expedientes sobre investigaciones de agentes de la Secretaría de Gobernación en todo el país relacionados con el tráfico de drogas desde por lo menos 1925 y durante la siguiente década; véase AGN, SEGOB, DGIPS. Para un recuento detallado sobre estas dependencias véase Salazar y Hernández, "Introducción". 
en un mundo que comenzaba a ver el tema de drogas desde el paradigma de la seguridad.

El artículo está dividido de la siguiente manera. La primera parte reconstruye la génesis de la policía sanitaria en México. El segundo apartado discute la naturaleza policiaca del Servicio de Narcóticos del DSP para posteriormente examinar, en la tercera sección, su fundación y desarrollo. En el cuarto apartado se analizan las principales prácticas y actividades de los agentes dentro y fuera de la ciudad de México. En la quinta sección se examina el papel de la Policía de Narcóticos en las campañas de erradicación de enervantes. El sexto apartado analiza la lenta pero progresiva pérdida de relevancia de la Policía de Narcóticos en las décadas de los cuarenta y cincuenta. Finalmente se examina la sustitución y desplazo de la Secretaría de Salubridad y Asistencia por la policía de la Procuraduría General de la República en lo relativo al control antinarcóticos.

\section{LOS ORÍGENES DE LA POLICÍA ANTINARCÓTICOS EN MÉXICO}

En 1841 se fundó el Consejo Superior de Salubridad, la entidad estatal encargada por varias décadas de guiar las políticas de salubridad e higiene del gobierno de México y encargada de supervisar los asuntos de farmacia. Para ello se crearon cuerpos subsidiarios, las llamadas "juntas subalternas de policía médica”. ${ }^{9}$ Es también el Consejo Superior de Salubridad el que sanciona, con la promulgación del primer Código Sanitario de los Estados Unidos Mexicanos de 1891, las funciones de la primera policía sanitaria. ${ }^{10}$ La Constitución de 1917 desaparece el

\footnotetext{
9 Ross, "From Sanitary Police”, p. 78. Aquí valga recordar que en el ecuador del siglo xix el concepto policía era más cercano a la idea del buen gobierno y la administración que a la del cuerpo de imposición de la ley. Véase Pulido, "Policía: del buen gobierno", pp. 1595-1642.

10 Aunque este y otros códigos similares harán mención de las funciones de la Policía Sanitaria (capítulo X), el tema de drogas o narcóticos todavía no se
} 
Consejo Superior de Salubridad pero mantiene el concepto de policía sanitaria, solo que ahora en el Departamento de Salubridad Pública (DSP), institución que en 1943, tras su fusión con el Departamento de Asistencia Pública, pasó a llamarse Secretaría de Salubridad y Asistencia (ssA).

Al DSP se le asignó la tarea de supervisar los asuntos relacionados con droguerías y boticas en el país. Esto incluía, entre otras tareas, la expedición de licencias de funcionamiento, así como la vigilancia de las importaciones y exportaciones de narcóticos legales. ${ }^{11}$ En 1925 se reafirmó la competencia del DSP en "el ejercicio de las funciones de Policía Sanitaria para impedir legalmente el comercio ilícito de drogas heroicas" ${ }^{12}$ Un año después, el Código Sanitario refrendó la autoridad del Dsp sobre "todo acto que se relacione con drogas enervantes" ${ }^{13}$ Más en concreto señala que el Departamento "directamente o por medio de sus delegados e inspectores que designe, deberá controlar en toda la República toda operación o acto que se relacione con drogas enervantes $\left[\ldots . . .^{14}\right.$

Estas disposiciones no aparecen desde el vacío. ${ }^{15}$ En los años anteriores se establecieron restricciones para el cultivo de adormidera, para la introducción y venta de opio, morfina, heroína y cocaína. Así, por ejemplo, tanto el comercio como la siembra de

menciona. Véase Aldo Francisco Contró, Héctor Anaya, y Carlos Zamudio, "La policía de salubridad en la ciudad de México: El caso de la división antinarcóticos 1920-1934" (III Congreso Nacional: estudios regionales y la multidisciplinariedad en la Historia, , 2014), p. 289.

11 DSP, Memoria de los trabajos, p. 358.

12 DOF, "Acuerdo determinando que compete al Departamento de Salubridad Pública, impedir el comercio ilícito de drogas heroicas" (10 marzo 1925). 13 DOF, “Código Sanitario de los Estados Unidos Mexicanos" (8 junio 1926), artículo 204.

14 DOF, "Código Sanitario de los Estados Unidos Mexicanos" (8 junio 1926), artículo 209.

15 Para un análisis del conjunto de las primeras leyes prohibicionistas SCHIEVENINI, "La prohibición de las drogas en México", pp. 57-68. Otro texto clave es CAmpos, "Degeneration and the Origins", pp. 379-408. 
marihuana quedaron estrictamente prohibidos en todo el país en 1920; ${ }^{16}$ la exportación de cocaína y derivados, heroína y morfina en $1923 ;{ }^{17}$ y la importación de opio, morfina, cocaína y otras drogas en 1925. ${ }^{18}$ En 1929 el Código Penal determinó sanciones específicas para aquellos responsables de "los delitos contra la salud" (artículo 507). ${ }^{19}$ Para 1931 se amplió el margen de las sanciones para fijarse de "entre seis meses a siete años y multas de 50 a 5000 pesos, a quien realizara a nivel local, actividades relacionadas con enervantes; $y$ de hasta 10 años y 10000 pesos por importaciones o exportaciones ilegales" (artículo 194). ${ }^{20}$

Todas estas leyes y decretos deben ser entendidos -aunque no necesariamente como consecuencia directa de- en el marco de la emergencia de un régimen internacional antinarcóticos y de la presión de Estados Unidos sobre México para regular el comercio de drogas. En todo caso, ese ciclo de disposiciones gubernamentales del primer lustro de los años veinte condujo a dos procesos: la explosión de la consignación de casos judiciales por delitos contra la salud y -lo que interesa a este texto- la emergencia de un aparato policial antinarcóticos dentro del DSP. ${ }^{21}$

${ }_{16}$ DOF, "Disposiciones sobre el cultivo y comercio de productos que degeneren la raza” (15 marzo 1920).

17 DOF, "Decreto prohibiendo la importación de drogas heroicas" (28 julio 1923).

18 DOF, “Acuerdo fijando las bases conforme a las cuales se procederá al remate de los narcóticos que provengan de un comercio ilícito" (9 marzo 1925). 19 DOF, "Código Penal para el Distrito y Territorios Federales en materia de fuero común, y para toda la República en materia de fuero federal” (5 oct. 1929).

${ }^{20}$ DOF, “Código Penal para el Distrito y Territorios Federales en materia de fuero común, y para toda la República en materia de fuero federal” (14 oct. 1931).

${ }^{21}$ Sobre los primeros casos judiciales por delitos contra la salud, véase el estudio de 231 expedientes de juicios relacionados con drogas entre 1926 y 1935 realizado por Ricardo Pérez Montfort. Pérez Montfort, Tolerancia y probibición, pp. 229-264. 
Es en este contexto que se crea en 1925 la Oficina de Inspección y Vigilancia Sanitaria dentro de la DSP, en otros textos referida como Inspección General. Tuvo como principal función la centralización de las tareas policiales de los agentes sanitarios, hasta ese momento repartidos entre las varias dependencias del DsP. ${ }^{22}$ Entre otras, en la Oficialía Mayor, la Secretaría General o la Jefatura del Departamento. Se trató de un primer esfuerzo centralizador de una institución que comenzaba a asumir tareas en una gran variedad de temas, algunos casi inimaginables en 1917; por nombrar uno, la persecución del transporte y producción de las “drogas heroicas”. 23

Todos los agentes asociados a la Inspección General tendrían que ser elementos con "antecedentes de moralidad y de competencia”. Todo el personal debía ser “normalmente moral, apartado del vicio a efecto de que sea un ejemplo fehaciente de lo que pretendemos que sean todos los miembros de nuestra sociedad". Por su parte, el inspector-jefe de la oficina-debía ser "un empleado culto y decente". ${ }^{24}$ "Por ser un organismo de nueva creación”, la Inspección carecía de reglamento. Sin embargo, éste "gradualmente" había ido "formándose, teniendo como base una serie de circulares que se giran en cada caso, según las circunstancias lo demandan". ${ }^{25}$

En términos orgánicos, la Inspección se subdividió en siete jefaturas de agentes especiales: de Narcóticos, de Sanidad, de Comestibles y Bebidas, de Leches, de Mercados y Plazas, de Higiene y Veterinaria, y de Agentes Foráneos -para 1935 se agregó el servicio de Pulques_ ${ }^{26}$ (véase organigrama, imágen 1 ). A todas las jefaturas se procuró

\footnotetext{
22 AHSSA, SP, SJ, c. 26, exp. 1.

23 DOF, “Acuerdo determinando que compete al Departamento de Salubridad Pública, impedir el comercio ilícito de drogas heroicas” (10 marzo 1925).

24 DSP, Memoria de los trabajos de 1925-1928, p. 448.

25 DSP, Memoria de los trabajos de 1925-1928, p. 448.

26 DSP, Memoria de los trabajos de1925-1928, p. 449.
} 
[...] darles un espíritu de uniformidad por lo que respecta a organización general, principios disciplinarios, maneras como debe servirse y tratarse al público, forma de administrar sus labores, etc.; pero respetando siempre, la peculiaridad de dichos servicios que por otro concepto, en la parte técnica acatan las instrucciones que emanan directamente de las Oficinas superiores correspondientes. ${ }^{27}$

\section{Imagen 1}

JEFATURA DE POLICÍA SANITARIA

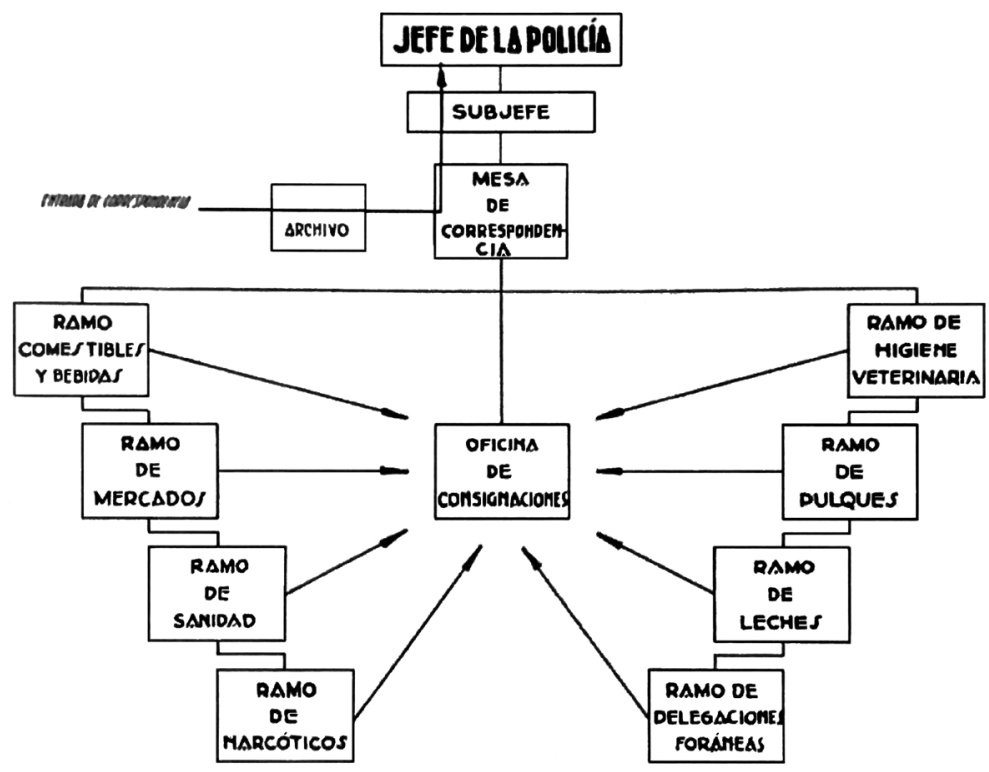

Fuente: Memoria de las labores realizadas durante 1934 a 1935 (Departamento de Salubridad Pública, 1935), p. 126.

27 DSP, Memoria de los trabajos de 1925-1928, p. 447. 
Antes de continuar vale la pena preguntarse por el tipo de policía que estaba en proceso de constituirse. La doctrina francesa clasifica a las policías en dos campos: policía general y policía administrativa. La primera tiende a la protección del orden público y comprende a los tipos tradicionales de policía: preventiva y judicial. La segunda vigila, cuida e inspecciona el exacto cumplimiento de reglamentos administrativos específicos. ${ }^{28} \mathrm{En}$ principio, toda ley o reglamento administrativo puede crear su policía para asegurar el cumplimiento de sus disposiciones. ${ }^{29}$ La Policía Sanitaria, que debía dar cumplimiento al Código Sanitario, es un ejemplo de policía administrativa; su función era de "controladora de la legalidad en toda la amplitud de su legislación”. ${ }^{30}$

Las cuatro funciones clásicas de la policía son cuatro: preventiva, persecutoria, sancionadora y de inspección. La primera (preventiva) supone el mantenimiento del orden público que, "según la doctrina francesa, implica la seguridad, la tranquilidad y la salubridad”. La segunda (persecutoria) comprende la comprobación del cuerpo del delito "con el objetivo de reunir los elementos necesarios para hacer viable el ejercicio de la acción penal". La tercera (sancionadora) consiste en aplicar correctivos y, “según la Constitución, sólo puede proceder contra las infracciones a los reglamentos de policía y buen gobierno, no así a las violaciones de las leyes administrativas”. Por último,

\footnotetext{
28 González, "Policía y Constitución”, p. 142.

29 González, "Policía y Constitución”, p. 142.

30 El modelo de policía administrativa tuvo bastante éxito en México. Para 1964 existían al menos 25 tipos de policías de ese tipo, incluyendo a las policías de Tránsito, Bancaria, Industrial, Forestal, de Comercio, etc. Véase González, “Policía y Constitución”, pp. 142-143.
} 
está la función de inspección, “que consiste en la vigilancia y supervisión del cumplimiento de las leyes y reglamentos administrativos". 31

En principio, cual policía administrativa, la Policía Sanitaria -y por tanto su Servicio de Narcóticos- no tenía funciones sancionadoras o persecutorias (segunda y tercera función). Esas facultades correspondían, según la letra del artículo 21 de la Constitución mexicana, solo a la Policía Judicial y al Ministerio Público. ${ }^{32}$ Por tanto, legalmente sus funciones se limitaban a prevenir pero, sobre todo, a inspeccionar (primera y cuarta función). Sin embargo, como veremos, en la práctica la división es más compleja y, acaso, en la nebulosidad de sus límites y alcances, está la explicación del porqué del ascenso y declive de la Policía de Narcóticos del DsP.

La función de inspección es connatural a la Policía Sanitaria y a su servicio de Narcóticos. La vigilancia de boticas y farmacias fue su cometido original. Sin embargo, las tareas de inspección y regulación de medicamentos importados o de surtimiento de éstos pasaron a ser secundarias frente a las tareas de control de drogas en la segunda mitad de los años veinte. Así, la función de inspección tomó un carácter más policial, que incluía la vigilancia de lugares donde se tuviera conocimiento de comercio o consumo de enervantes, así como de los mismos usuarios de drogas. Como era de esperarse, la implementación de estas medidas -en algunos casos llevadas a cabo por farmacéuticos de profesión- resultaba del todo ajena para el personal antinarcóticos que no siempre aceptaban con agrado llevar a cabo funciones

${ }^{31}$ La tipología y frases entrecomilladas pertenecen a González, "Policía y Constitución", p. 150.

${ }^{32}$ La Policía Judicial fue creada a través del Código de Procedimientos Penales de 1880 y "no se entendió como un cuerpo policiaco, sino como una función de pesquisa desarrollada por autoridades políticas y por los jueces mismos de instrucción”. GonzÁlez, "Policía y Constitución”, p. 146. 
de índole policial. ${ }^{33}$ El término común que utilizaba la Policía Sanitaria era practicar visitas domiciliarias que, en principio, solo podían realizarse con una orden firmada por el jefe del Servicio de Química y Farmacia. La pregunta, sin embargo, estaba presente: ¿ ¿podía acaso diferenciarse esa dimensión del trabajo de inspección de las funciones de prevención, sanción y persecución?

Los constituyentes de 1917 ya habían anticipado aquella tensión. En el ya mencionado artículo 21 se establece la diferencia entre delito y lo que se llamó infracción de policía. Mientras los delitos eran considerados hechos violatorios de una ley penal y por tanto su calificación y castigo materia de autoridad judicial, las infracciones de policía eran aquellas que por riesgo a convertirse en una carga abrumadora de la policía judicial pasaban al ámbito de las autoridades administrativas; es el caso del Código Sanitario a la Policía de Salubridad. En concreto, la redacción original del artículo 21 constitucional permitía "el castigo de las infracciones de los reglamentos gubernativos y de policía; el cual únicamente consistiría en multa o arresto hasta por treinta y seis horas; pero si el infractor no pagare la multa que se le hubiese impuesto, se permutará ésta por el arresto correspondiente, que no excederá en ningún caso de quince días [...]" ${ }^{34}$ Este subterfugio ponía en entredicho el monopolio de la Policía Judicial en las funciones de persecución y sanción, mismas que, como se ve, son inseparables de la inspección.

De esta manera, el Servicio de Narcóticos sí podía detener a delincuentes infraganti, realizar el reporte de hechos y remitir a los sospechosos al Ministerio Público. Entremedio, el Servicio Jurídico del DsP levantaba un acta por cada detención y daba curso a las averiguaciones previas correspondientes. ${ }^{35}$

33 Véase el caso del inspector de Boticas Ramón Arteaga Talán, en AHSSA, $S P, E P$, c. 14, exp. 14.

${ }^{34}$ Constitución Política de los Estados Unidos Mexicanos, 1917, artículo 21.

${ }^{35}$ AHSSA, SP, SJ, c. 26, exp. 1. 
Además, desde el Servicio Jurídico se determinaba el destino del detenido. Este podía ser dejado en libertad, ser enviado al Hospital Federal de Toxicómanos o ser consignado ante las autoridades judiciales. ${ }^{36}$

El DsP en su conjunto sí tenía facultades sancionadoras. Esto es, la capacidad para imponer multas o realizar decomisos con fundamento en leyes administrativas. Los reportes policiales dan cuenta de inspectores farmacéuticos adscritos a las Delegaciones Federales de Salubridad (véase infra), así como de agentes del Servicio de Narcóticos, participando en incautaciones de drogas y en campañas de erradicación de cultivos.

En 1934, el Código de Procedimientos Penales estableció que el Ministerio Público "se pondrá inmediatamente en relación con el Departamento de Salubridad Pública” cada vez que tenga conocimiento "de que una persona ha hecho uso de drogas, substancias, semillas o plantas enervantes" (artículo 523). ${ }^{37}$ Según el código referido, el DSP y sus agentes tenían la facultad de determinar si los inculpados eran toxicómanos o no. En el último caso, se ejercitaría acción penal; en el primero, "no se hará consignación a los tribunales" (artículo 524). ${ }^{38}$ Así, al desistirse de la acción penal, el Ministerio Público ponía al detenido a disposición del Departamento de Salubridad "o del delegado de éste que corresponda, para que se le interne en el hospital o departamento especial destinado a toxicómanos por el tiempo que sea necesario para su curación" (artículo 526).

Por último, la Policía Sanitaria también podía fungir como auxiliar de la Policía Judicial. Esto es, podía tener actividad persecutoria, pero solamente si ésta era coordinada por los agentes del Ministerio Público y de la Policía Judicial propiamente dicha.

36 AHSSA, SP, SJ, c. 43, exp. 4.

37 DOF, “Código Penal de Procedimientos Penales” (30 agosto 1934).

38 DOF, “Código Penal de Procedimientos Penales” (30 agosto 1934). 
En resumen: la Policía Sanitaria y su Servicio de Narcóticos nació como policía administrativa. Su función original fue -así- de inspección. Sin embargo, la naturaleza de su trabajo fue tal que asumió progresivamente funciones persecutorias y sancionadoras amparadas en el artículo 21 de la Constitución, aunque siempre bajo la tutela de las autoridades sanitarias. Con el tiempo y la codificación penal del tráfico de drogas, estas funciones iban a ponerse en entredicho por la policía judicial, entidad que finalmente reclamaría para sí la jurisdicción de los delitos relacionados.

\section{EL SERVICIO DE NARCÓTICOS: \\ SU FUNDACIÓN Y DESARROLLO}

El Servicio de Narcóticos, también conocido como Jefatura de Narcóticos, se fundó así en 1925 como uno de los siete componentes que constituían la Oficina de Inspección y Vigilancia Sanitaria. Antes de su creación, "los escasos" trabajos sobre "el particular" eran atendidos únicamente por dos agentes que "indistintamente recibían órdenes de diversas oficinas del mismo departamento, sin que hubiera unidad en el ordenamiento de sus laborales, sin que tuvieran una oficina en que poder preparar sus trabajos, ni un solo útil para dar cima a los mismos". ${ }^{39}$ Las condiciones debían ser bastante precarias: las credencias estaban redactas "en los mismos términos en que estaban las de todos los empleados de la Institución [...]”. Ello daba pie a que "traficantes y consumidores de tóxicos" tuvieran "el campo enteramente abierto". 40

La fundación del Servicio de Narcóticos implicó la designación de "un jefe y un número determinado, aunque reducido

39 DSP, Memoria de los trabajos 1925-1928, p. 449.

40 DSP, Memoria de los trabajos 1925-1928, pp. 449-450. 
por entonces, de agentes [...]". ${ }^{41}$ Se señaló un "lugar decoroso" para el establecimiento de la oficina "en toda regla" y se proveyó a los agentes de "credenciales amplias que los capacitaban para desempeñar su trabajo sin ninguna dificultad" y un carro "con el cual [los agentes] llevaron sus pesquisas no sólo a todos los rincones de la ciudad, sino a todos los confines del Distrito Federal y de vez en cuando fuera de éste" ${ }^{42}$ En resumen: la oficialización del servicio de Narcóticos significó lo siguiente: en términos administrativos, la centralización de tareas; en términos logísticos, la obtención de un local decoroso, credenciales y un carro.

Como se ha señalado ya en distintas historias sociales y culturales del narcotráfico, e incluso en alguna novela policiaca, durante los años veinte del siglo pasado, uno de los principales blancos de los policías de narcóticos en la ciudad de México eran los fumaderos de opio propiedad de miembros de la población china. ${ }^{43} \mathrm{Su}$ radio de acción se limitó casi siempre al Distrito Federal. Las Memorias del DSP dan cuenta de las confiscaciones de 1926 en la capital del país: "2,159.33 gramos de cocaína, 2,299.78 gramos de heroína, 1,339.36 gramos de morfina, $34,721.35$ gramos de opio y 424,934.38 gramos de marihuana". ${ }^{44}$ Estas detenciones respondieron a políticas de drogas con connotaciones clasistas y racistas. La población de origen asiático que llegó a México no concordó con los ideales identitarios de las élites posrevolucionaras y se les relacionó con el vicio y "la degeneración de la raza". ${ }^{45}$ Lo anterior derivó en una campaña "antichina" que implicó no solamente la persecución de la población china por su supuesta relación con el consumo y tráfico de drogas, sino la

\footnotetext{
${ }^{41}$ DSP, Memoria de los trabajos 1925-1928, p. 450.

42 DSP, Memoria de los trabajos 1925-1928, p. 450.

43 Véase la extraordinaria obra BERNAL, El complot mongol.

${ }_{44}$ DSP, Memoria de los trabajos, p. 451.

45 Gómez, "La hostilidad racista", pp. 401-410.
} 
expulsión de México de más de mil chinos entre 1911 y 1940 por considerarse "extranjeros perniciosos". ${ }^{46}$

A mediados de 1929 el entonces jefe del Departamento, doctor Aquilino Villanueva, "desmembró" a la Policía Sanitaria tras algunas quejas de "Sres. Jefes de Servicio" que habían "manifestado tener ciertas dificultades" con los agentes sanitarios. Sin embargo, "poco tiempo después, dándose perfectamente cuenta del error cometido, volvió a ordenar la integración dándole todo su apoyo y protección". ${ }^{47}$ Lo cierto es que desconocemos tanto las razones reales de tal desmembramiento, así como el tiempo de su duración. Sabemos, en cambio, que unos meses después se nombró jefe de la Policía Sanitaria a Julio M. González. Al cuerpo policiaco se le asignaron oficinas en el edificio que anteriormente ocupaba la imprenta del DSP. ${ }^{48}$

Hacia 1930 la Policía Sanitaria del DsP continuaba enclavada en la Oficina de Inspección y Vigilancia Sanitaria y estaba integrada por un jefe de la Policía, nueve jefes de agentes y unos 200 agentes divididos en ocho ramos: Jefatura de Policía (6), Comestibles y Bebidas (32), Delegaciones Foráneas (45), Mercados y Plazas (20), Narcóticos (12), Higiene Veterinaria (12), Leches (41) y Sanidad (26). ${ }^{49}$ Las funciones nominales de la docena de agentes del ramo Narcóticos eran fundamentalmente cuatro:

Practicar visitas domiciliarias a las habitaciones en donde se tiene conocimiento se comercia con drogas enervantes, aprehendiendo a los traficantes y decomisando las drogas.

Vigilar a los viciosos y traficantes, a fin de localizar los lugares en donde se reúnen para inyectarse drogas.

\footnotetext{
46 Yankelevich, "Extranjeros indeseables en México", pp. 693-744. Para un estudio completo sobre la discriminación de la población china en México, véase también Chang, Chino: Anti-Chinese Racism in Mexico.

47 AHSSA, SP, SJ, c. 26, exp. 1.

48 AHSSA, SP, SJ, c. 5, exp. 31.

${ }^{49}$ AHSSA, SP, SJ, c. 26, exp. 1.
} 
Remitir a los traficantes y viciosos a la Cárcel General del Belén o a la Penitenciaría, una vez levantadas las actas correspondientes por el Servicio Jurídico.

Vigilar las Boticas y Farmacias, en las que se tiene conocimiento se expenden a viciosos y traficantes drogas enervantes, y en los casos en que se obtienen datos positivos, se procede a practicar visita domiciliaria con la correspondiente orden por escrito del C. Jefe del Servicio de Química y Farmacia. ${ }^{50}$

En febrero de 1930, el entonces jefe de la Policía de Salubridad, Julio M. González, sostenía en su informe de labores que la docena de agentes del "ramo de Narcóticos" era claramente insuficiente a la luz de "la gran cantidad de viciosos y traficantes de drogas enervantes que existe en esta Ciudad”. Proponía que, cuando menos, se incrementase a 24 el número de agentes del ramo. ${ }^{51}$ Con todo, según datos del jefe del Departamento Jurídico del Dsp Francisco Vázquez Pérez, los agentes del ramo Narcóticos "producían un promedio de tres averiguaciones previas diarias, con aprehensiones de toxicómanos y traficantes en todas ellas". 52

Hacia 1931, la falta de personal y de recursos era la principal queja del DsP, que pedía la cooperación de las secretarías de Guerra, Gobernación y Hacienda. Al ejército pedía “que preste el auxilio de la fuerza pública, como lo ha venido haciendo cada vez que se le ha requerido". Además, le pide que "coadyuve a la extirpación del uso de las drogas entre los miembros del ejército”. Las peticiones a la Secretaría de Gobernación son igualmente directas: "que auxilie con sus servicios especiales a las autoridades de Salubridad [...y] que excite a los gobernadores de los Estados a que presenten, dentro de sus respectivas

${ }^{50}$ AHSSA, SP, SJ, c. 26, exp. 1.

51 AHSSA, SP, SJ, c. 26, exp. 1.

52 AHSSA, SP, SJ, c. 26, exp. 1. 
jurisdicciones, un auxilio semejante". Por último, precisa la cooperación de la Secretaría de Hacienda para "el control de los narcóticos por las Aduanas y, de ser posible, aumentando las partidas que demandan estos nuevos servicios". ${ }^{53}$

Hacia abril de 1932 la Oficina de Inspección y Vigilancia Sanitaria reportó que había disminuido el número de agentes totales de la Policía de Salubridad a 199. En el ramo de Narcóticos había 13 personas adscritas: el jefe Benjamín Vélez y 12 agentes asignados a tres grupos distintos. ${ }^{54}$ Ante esa situación, el doctor Gastón Melo, que ocupaba el cargo de jefe del DSP, convocó a varias reuniones con todas las secciones del Departamento, para discutir los recursos, las funciones y la organización de la Policía de Salubridad.55

En octubre de 1932 se publicó en el Diario Oficial de la Federación el Reglamento de la Policía Sanitaria del Departamento de Salubridad Pública. Borradores del reglamento existían al menos desde febrero de $1930 .{ }^{56}$ En este documento se establecía que la Policía Sanitaria comprendía "la totalidad de los servicios de investigación y vigilancia sobre cumplimiento de los preceptos del Código Sanitario, sus reglamentos y demás disposiciones sobre higiene, y las otras funciones de carácter policiaco, que le encomienden los jefes de los Servicios Sanitarios". ${ }^{57}$ En cuanto a la organización, el Reglamento establecía que la Policía Sanitaria estaría integrada por un jefe, un subjefe "y los agentes de diversas categorías que el presupuesto señale”. Además de clarificar las tareas del jefe y el subjefe, el Reglamento señala que "los agentes desempeñarán únicamente labores de investigación y vigilancia y dependerán en el desarrollo de sus funciones policiacas y en lo administrativo, del jefe de la Policía Sanitaria”. Solamente

\footnotetext{
${ }^{53}$ AHSSA, SP, SJ, c. 27, exp. 8.

${ }^{54}$ AHSSA, SP, SJ, c. 26, exp. 1.

${ }_{55}$ AHSSA, SP, SJ, c. 26, exp. 1.

56 AHSSA, SP, SJ, c. 26, exp. 1.

57 AHSSA, SP, SJ, c. 30, exp. 12.
} 
serían nombrados agentes que acreditasen su "honradez y buena conducta, por constancia de dos personas de reconocida honorabilidad". La aptitud de los candidatos sería examinada con la sustentación de certificados de la Escuela de Salubridad. Se estableció que los agentes trabajarían en grupos dependientes de un "jefe de grupo" que a su vez sería asignado por el jefe de la Policía. Este último debía rendir "diariamente el parte de novedades que hubieran ocurrido el día anterior al Oficial Mayor, quien dará cuenta a la Jefatura y a la Secretaría General [del DSP]" ${ }^{58}$

En una junta celebrada el 25 de enero de 1934 a la que asistieron el Oficial Mayor y otros Jefes de Servicio del DsP, se acordó que la "totalidad de las labores de investigación y vigilancia en materia de tráfico ilícito de estupefacientes corresponde a la Oficina de Inspección y Vigilancia Sanitarias, cuyo jefe encauzará estas investigaciones, mediante los agentes a su mando y bajo su responsabilidad". Asimismo, también se acordó que el jefe de la Oficina de Inspección y Vigilancia Sanitarias seguirá recibiendo los reportes que le rindan sus agentes y "los consignará al Servicio Jurídico para que éste practique la investigación administrativa previa y recabe del C. Secretario General el acuerdo sobre la consignación que corresponda". ${ }^{59}$

\section{LOS AGENTES, SUS PRÁCTICAS Y SUS ACTIVIDADES} EN LOS AÑOS VEINTE

El AHSSA resguarda algunos de los expedientes de los agentes del Servicio de Narcóticos. La revisión de estos documentos presenta dos comunes denominadores entre dichos agentes: por un lado, su nulo entrenamiento policial previo y, por otro lado, su brevísima permanencia en el cargo. A continuación se tratarán ambos elementos.

58 AHSSA, SP, SJ, c. 30, exp. 12.

59 AHSSA, SP, SJ, c. 26, exp. 1. 
Los agentes -todos eran hombres- eran jóvenes; pocos eran los que rebasaban los 30 años de edad. Aunque no contaban con entrenamiento policial sí tenían la obligación de asistir a la Escuela de Salubridad. Ahí se impartían una variedad de cursos que iban desde la enseñanza de los planos y la nomenclatura de las calles de la ciudad de México, las causas y efectos del alcoholismo, la intoxicación por marihuana y otras toxicomanías, hasta la aplicación de legislaciones sanitarias. ${ }^{60}$ Lo anterior es evidencia de que, si bien no sufrió un proceso de profesionalización ni sustentó carreras burocráticas estables, la Policía de Narcóticos sí mantuvo un programa de entrenamiento sostenido bastante excepcional que la distingue de otras organizaciones policiales del país.

En algunos casos los agentes -los menos- tenían experiencia laboral en otras oficinas del DSP aunque en departamentos muy distantes al sector de narcóticos; en la mayoría de los casos, sin embargo, llegaban al Servicio por recomendación de otros funcionarios del mismo departamento. La práctica no era una particularidad del DSP: prácticamente todos los cuerpos policiales de la época (por no hablar del presente) estaban constituidos por gente recomendada. La práctica era tan usual que el nombre y posición del aval aparecían en la ficha respectiva de cada nueva contratación.

Un buen botón de muestra es Ignacio Campos, sujeto al que se le expidió su nombramiento como agente de la "Policía Sanitaria, Ramo Narcóticos” el 1o de enero de 1926. Campos había sido agente sanitario del Servicio de Enfermedades Transmisibles y contaba con buenas referencias de Bernardo Gastélum, jefe del DsP. ${ }^{61}$

60 AHSSA, SP, SJ, c. 11, exp. 28. En relación a la Escuela de Salubridad, véase Gudiño-Cejudo, Magaña-Valladares y Hernández Ávila, “La Escuela de Salud Pública”, pp. 81-91.

61 AHSSA, SP, EP, c. 12, exp. 28. 
Como se explicó anteriormente, el otro común denominador era el breve tiempo que los agentes permanecían en funciones, por lo general unos meses -a veces solo un par de semanas-. Las explicaciones oficiales son siempre variadas, aunque las reales nunca las conoceremos con certeza. El sueldo de 5 pesos diarios era la media dentro de la administración federal y las condiciones no parecen haber sido especialmente duras. Las acusaciones de corrupción, sin embargo, estuvieron presentes desde el principio.

Ignacio Campos-véase supra-apenas trabajó por cuatro meses. En abril de 1926 fue expulsado del cuerpo por "graves faltas y probables delitos cometidos". ${ }^{62}$ Lamentablemente su expediente personal no deja ver las razones concretas de su despido.

Antonio Canedo Ortega, contratado en febrero de 1926, renunció un mes después "en virtud de atender asuntos personales que exigen su presencia". ${ }^{63}$ En realidad, al agente se le achacaba el haber desertado en horas de servicio durante una operación policial en el Centro Histórico de la ciudad de México. Canedo Ortega tuvo que devolver así su credencial, placa de policía, pistola y linterna eléctrica "que se le facilitaron" cuando ingresó al servicio. ${ }^{64}$

Alberto L. Chávez también fue recomendando por el jefe del DSP en febrero de 1926. A principios de ese mes se le expidió su nombramiento y apenas el 23 de febrero renunció a su cargo. Según le comentó Chávez al inspector de Narcóticos, Francisco César Morales, los horarios le hacían imposible continuar con su prioridad: terminar el último año de su carrera de ingeniero mecánico electricista. Se aceptó su renuncia. ${ }^{65}$

Pedro Incháustegui fue nombrado "Agente Sanitario Viajero de la Delegación Federal de Salubridad en Zacatecas, Zacatecas"

62 AHSSA, SP, EP, c. 12, exp. 28.

${ }^{63}$ AHSSA, $S P, E P$, c. 13, exp. 23.

${ }^{64}$ AHSSA, $S P, E P$, c. 13, exp. 23.

${ }^{65}$ AHSSA, SP, EP, c. 20, exp. 25. 
el 31 de mayo de 1927. ${ }^{66}$ Incháustegui tenía 40 años y ningún otro empleo registrado; se le asignó un salario de 4 pesos diarios. Dos meses después, en julio de 1927, y sin justificación explícita, obtuvo un ascenso al ser nombrado "Agente de Primera para la Policía de Narcóticos, en los Estados”. Su sueldo subió a 6 pesos diarios. ${ }^{67} \mathrm{Su}$ metódico ascenso terminó en diciembre de 1927. "Ciertos informes" llegaron a manos del jefe del Servicio de Inspección de Narcóticos quien, tomando en cuenta la opinión del Servicio Jurídico Consultivo, decidió cesar de sus funciones a Incháustegui. ${ }^{68}$ En este, como en otros casos, los archivos callan.

La prohibición generó un mercado ilegal que a su vez tuvo efectos corruptores en todas las áreas del servicio público. La Policía de Narcóticos del DSP no fue inmune a estos efectos y tuvo los mismos problemas de corrupción que los cuerpos de seguridad antinarcóticos que le antecedieron y sucedieron. En ello no parece destacarse. Otros trabajos ya han detallado varios casos en que estuvieron envueltos sus agentes dentro y fuera de la ciudad de México. ${ }^{69}$ No interesa aquí repetirlos sino señalar el consenso bibliográfico: el DSP y su sección policial fueron presa desde muy temprano de casos de corrupción administrativa; más aún, la participación de funcionarios de la Policía de Narcóticos en redes criminales es congénita al nacimiento de la corporación.

Ya en 1928 -apenas tres años después de la fundación de la Policía de Narcóticos- el DSP admitía en sus memorias un mea culpa bastante singular para una publicación oficial:

En esta corporación, como en casi todas, suelen de vez en cuando filtrarse elementos que, aunque aparentemente presten una magnífica ayuda, en el fondo lo único que les preocupa es su medro

66 AHSSA, SP, EP, c. 39, exp. 17.

67 AHSSA, SP, EP, c. 39, exp. 17.

68 AHSSA, SP, EP, c. 39, exp. 17.

69 Véase Olvera, "Policías, toxicómanos y traficantes”, pp. 188-189. 
Imagen 2

CREDENCIAL DE PEDRO INCHÁUSTEGUI

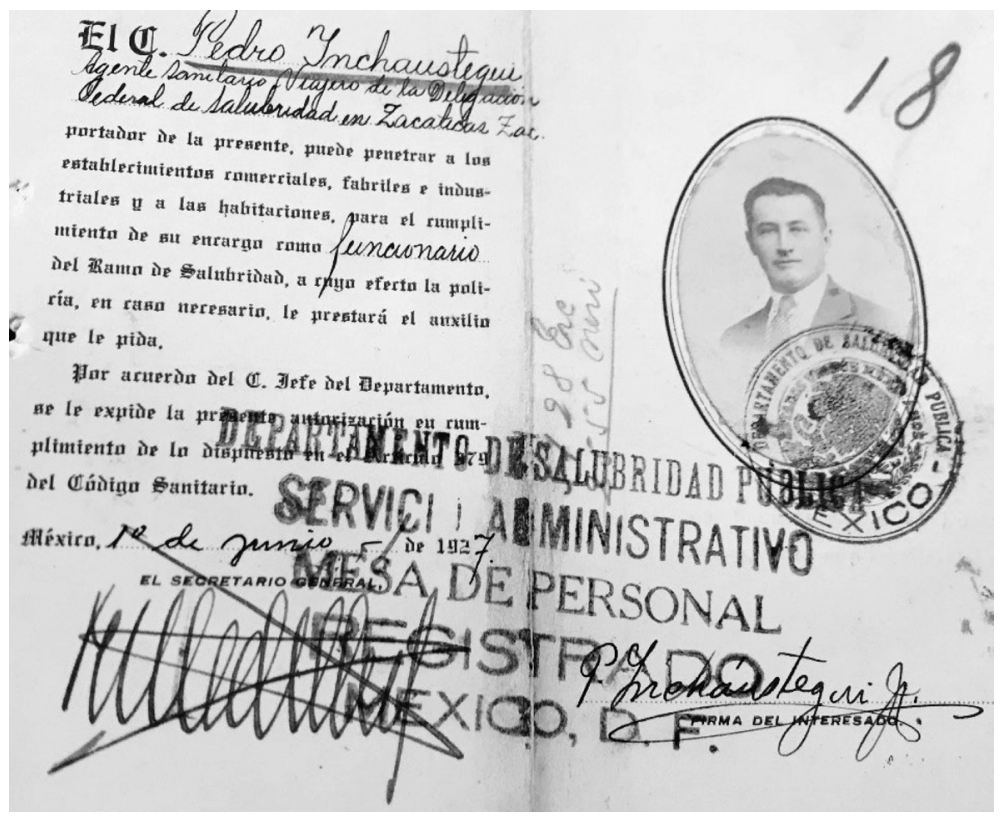

Fuente: Archivo Histórico de la Secretaría de Salud, fondo Salubridad Pública, Expedientes Personales, c. 39, exp. 17.

individual. Varios individuos que como inspectores figuraron en el personal de esta dependencia faltaron al compromiso que habían contraído al protestar cumplir y hacer cumplir las leyes que nos rigen, y descubiertos en su delito todos han sido castigados, desde luego exonerándoseles del servicio, y cuando las circunstancias lo han requerido, consignándolos a las autoridades competentes. ${ }^{70}$

Precisamente porque la corrupción comenzó a dañar el prestigio de la Policía de Narcóticos desde su nacimiento, se

70 DSP, Memoria de los trabajos, p. 452. 
establecieron mecanismos de control que intentaron reducir los alcances de la penetración criminal, así como aplicar castigos a los responsables. Uno de estos mecanismos fue el uso de la sección de Servicios Confidenciales del DSP para investigar denuncias contra miembros de la corporación. El caso más notable es la documentación hecha por Julián Meza Terán -jefe de los Servicios Confidenciales del DSP- de las actividades delincuenciales del otrora director de la Policía de Narcóticos en la ciudad de México, Raúl Camargo.

A Camargo se le acusaba de proteger a varios traficantes de droga en la ciudad de México a finales de la década de 1920. En atención a estos rumores, Meza Terán construyó un expediente en el que describió cómo Camargo había sido cooptado por una "matriz de una sociedad de chinos conocida con el nombre de la Lung Sing”. Según la descripción de Meza Terán, esta organización habría encontrado en Camargo "un magnífico elemento para utilizarlo en sus maniobras, comprendiendo perfectamente su fondo moral y la forma en que podría serles útil". ${ }^{71}$ Del mismo modo, Meza Terán describió un incipiente sistema de protección a ciertos traficantes del que Camargo era parte. En particular describe cómo Félix y Othón Sánchez -dos "grandes comerciantes de drogas"- pagaban una cuota a Camargo y a los agentes a su cargo para que sus vendedores no fueran molestados por la policía. ${ }^{72}$ El expediente de Meza Terán, que incluía otros casos que involucraban a Camargo, fue remitido a la dirección del DsP. Lo relevante del caso es que Camargo fue efectivamente destituido en julio de 1929 y hacia marzo de 1930 tenía un proceso instruido en el Juzgado Tercero de Distrito. ${ }^{73}$

71 AHSSA, SP, SJ, c. 17, exp. 14.

72 AHSSA, SP, SJ, c. 17, exp. 14.

73 AHSSA, SP, SJ, c. 17, exp. 14. 


\section{ACCIONES ANTINARCÓTICOS}

FUERA DE LA CIUDAD DE MÉXICO

Fuera de la ciudad de México eran los inspectores farmacéuticos adscritos a las delegaciones federales de Salubridad quienes regulaban el surtimiento de medicamentos y la expedición de permisos en boticas y farmacias. Auxiliado por los inspectores sanitarios, el inspector farmacéutico de cada delegación "vigila[ba] el tráfico de drogas enervantes, inspecciona[ba] detenidamente los libros de narcóticos y [perseguía] sin tregua a los vendedores clandestinos". ${ }^{74}$

Los telegramas y reportes enviados por los delegados sanitarios desde los diferentes estados del país dan cuenta de las dudas que tenía los delegados sanitarios con relación a la manera de redactar las actas de narcóticos decomisados, los límites y alcances de las funciones legales de las autoridades sanitarias locales, el procedimiento formal contra médicos y boticas que despachaban drogas, así como las solicitudes de morfina que médicos y adictos hacían a la delegación. Las muchas dudas son evidencia del poco conocimiento que tenían los inspectores sobre el tema de drogas narcóticas, ciertamente un tema de interés menor comparado con el resto de las funciones que debían cumplir. Los telegramas -que podían tardar días en ser atendidos- eran recibidos y respondidos por el Servicio Jurídico del DsP, desde cuyas oficinas se dictaban instrucciones precisas sobre cómo proceder en casos de cultivo, tráfico o posesión de drogas.

Los archivos también dan cuenta de incipientes, si bien ocasionales, acciones policiacas realizadas por funcionarios adscritos a delegaciones federales del DSP en Mazatlán, Nogales, Villa Acuña y Chihuahua hacia finales de la década de 1920 y principios de 1930. Al igual que en la ciudad de México, el blanco de ataque eran las "casas donde habitaban chinos", lugares

74 DSP, Memoria de los trabajos, p. 85. 
donde ocurrían frecuentes decomisos de heroína y agujas hipodérmicas. ${ }^{75}$ Las incautaciones realizadas por las distintas delegaciones sanitarias en los estados eran enviadas a las oficinas centrales del DSP. Primero, se levantaba un acta enumerando los productos y cantidades recibidas. En segundo lugar las sustancias eran analizadas por el Servicio de Química y Farmacia para, finalmente, ser depositadas en la caja fuerte de la dependencia. ${ }^{76}$

En otras ocasiones, los delegados sanitarios -en cumplimiento con el artículo 510 del Código Sanitario- llevaron a cabo las primeras acciones de erradicación de cultivos de amapola y marihuana en el país. Así, por ejemplo, en marzo de 1925 el delegado sanitario del DSP en Nogales afirmó haber "destruido un plantío de amapolas” en esa región. ${ }^{77}$ En abril de 1925 el delegado sanitario en Mazatlán (Sinaloa) reportó a su superior en el Distrito Federal la destrucción "total” de un plantío de adormideras, así como la aprehensión de "cinco chinos" quienes fueron puestos "a disposición del juzgado del distrito quien ya les instruye el proceso respectivo" ${ }^{78}$

Por esas mismas fechas el periódico El Demócrata Sinaloense divulgó la presencia de plantíos de adormidera en las cercanías de Acaponeta, Nayarit. En esa región no había delegados sanitarios, pero la presidencia municipal "comisionó al ciudadano Inspector de la Policía para que, en unión de una escolta proporcionada por la Jefatura de Armas, pasara al lugar indicado e hiciera las averiguaciones correspondientes $[\ldots]$ ". ${ }^{79}$ Una vez en el lugar señalado de nombre La Cofradía, a cargo del señor Manuel Chang, el inspector recogió muestras del plantío que a su vez fueron enviadas al Laboratorio de Química y Farmacia del

\footnotetext{
75 AHSSA, SP, SJ, c. 4, exp. 12.

76 Al respecto consúltense varios expedientes de la c. 4 del AHSSA, SP, SJ.

77 AHSSA, SP, SJ, c. 4, exp. 1.

78 AHSSA, SP, SJ, c. 4, exp. 2.

79 AHSSA, SP, SJ, c. 4, exp. 3.
} 
DSP. ${ }^{80}$ Tras confirmarse que se trataba de adormidera, desde el Distrito Federal se ordenó al juez auxiliar de El Oro la incineración del plantío "en presencia de la Autoridad Municipal” ${ }^{81}$ No debemos engañarnos; resulta difícil pensar que todos los casos se resolvieran de similar manera; los archivos solo dejan ver la narrativa oficial, bastante lejana de los casos de corrupción que ya otros autores han identificado cuando se trata de erradicar plantas ilícitas. ${ }^{82}$

En agosto de 1931, el delegado sanitario en Colima, doctor Carlos Ortiz Mariotte, informó al jefe del Departamento de Salubridad de la detención de un tal Juan Flores, acusado de poseer 3200 gramos de marihuana en su casa. Según el acusado, las plantas no eran para traficar, sino que estaban "destinadas a la preparación de unas cataplasmas pasa su esposa que padece de reumatismo y que estaban expuestas al sol con el fin de secarlas para conservarlas mejor". ${ }^{83}$ Se trata de un caso que -como muchos otros- ejemplifica la falta de conocimiento y experiencia que tenían los delegados sanitarios sobre cómo actuar en estas circunstancias. ${ }^{84}$ Se trataba, según escribió Ortiz Mariotte en otro oficio, del "primer caso que se presenta en esta delegación", por lo cual se pedía al jefe del Departamento de Salubridad Pública que "se sirva indicarme el procedimiento que debe seguirse en cada caso, así como dotar a esta Oficina de los reglamentos e instrucciones correspondientes a fin de obrar con apego a las leyes y reglamentos respectivos" ${ }^{85}$ Finalmente, a pesar de la

\footnotetext{
${ }^{80}$ Ramón R. Nuño, Carta a Ciudadano juez de primera instancia, 3 de abril de 1925. AHSSA, SP, SJ, c. 4, exp. 3.

${ }^{81}$ AHSSA, SP, SJ, c. 4, exp. 3.

82 Véase, por ejemplo, Astorga, “Traficantes de drogas, políticos y policías”. 83 AHSSA, SP, SJ, c. 4, exp. 12.

${ }^{84}$ Existen consultas de Delegados Sanitarios y contestaciones de las oficinas centrales del Dsp de diversas ciudades como Tijuana, Chihuahua, Ciudad Juárez, Torreón, Matamoros, Tampico, San Luis Potosí, Veracruz, Morelia, Colima, etcétera. Véase documentación de las cajas 8, 6, 14, 17 del AHSSA, SP, SJ. ${ }^{85}$ AHSSA, SP, SJ, c. 4, exp. 12.
} 
defensa de Flores, se le impuso una multa de diez pesos y se le decomisó la marihuana. Las ordenes desde el Distrito Federal eran claras: proceder a la destrucción de las plantas, levantar el acta respectiva y enviar copia al Departamento.

En otros casos el DSP optó por comisionar a miembros de la Policía Sanitaria a investigar fuera de la ciudad de México. Destaca el caso del "agente confidencial Sr. Juan Requena", quien durante 1931 realizó profundas indagaciones sobre traficantes en los estados de Chihuahua, Durango, Coahuila y Veracruz. En la frontera norte Requena colaboró con autoridades estadounidenses, con las que logró la detención de varios "individuos que constantemente pasaban el puente internacional [a El Paso, Texas] y que se dedicaban al tráfico de drogas enervantes". Además, informó sobre la existencia en la ciudad de Chihuahua de varios fumaderos de opio, así como de los traficantes que "surtían a los chinos de Ciudad Juárez". Llama también la atención su apunte sobre "norteamericanos" que en aeroplanos traficaban a gran escala y sobre cómo era "increíble la forma en que se trafica[ba] en la frontera". ${ }^{86}$

Requena también realizó investigaciones más minuciosas. En su reporte sobre su visita a Coahuila, el agente informó sobre la existencia de Antonio Wong Yin, presunto traficante chino que mantenía tratos cercanos con el presidente municipal de Torreón, Francisco Ortiz Garza, así como una relación de compadrazgo con el gobernador del estado, Nazario Ortiz Garza. Asimismo, acusó al jefe de operaciones militares, el general Jesús García Gutiérrez, de colaborar estrechamente con otro traficante de narcóticos. Ante aquel panorama, Requena y otros agentes del DSP decidieron "suspender sus investigaciones hasta no recibir instrucciones, temiendo no tener el suficiente apoyo de las autoridades civiles y militares en el estado" ${ }^{87}$

\footnotetext{
86 AHSSA, SP, SJ, c. 28, exp. 6.

87 AHSSA, SP, SJ, c. 28, exp. 6.
} 
La investigación de Requena finalizó con la elaboración de una lista de casi 80 personas presuntamente implicadas en el contrabando de narcóticos en todo el país, entre las que se encontraban expresidentes municipales, otros políticos, empresarios, varios extranjeros y la famosa traficante Ignacia Jasso, alias " $\mathrm{La}$ Nacha". ${ }^{88} \mathrm{El}$ alcance de las investigaciones y los intereses que tocó el agente confidencial del DSP fueron de tal magnitud que muy probablemente derivaron en amenazas contra su persona. Entre los documentos del Archivo de Salubridad Pública hay una nota anónima, en un pedazo de papel de color café, en la que aún puede leerse: "Requena. Procure largarse, si quiere vivir". ${ }^{9}$

\section{EL DEPARTAMENTO DE SALUBRIDAD PÚBLICA \\ Y LAS CAMPAÑAS DE ERRADICACIÓN DE ENERVANTES}

La Memoria del DSP de 1938 dedica un par de páginas a reseñar las actividades de la Oficina General de la Campaña contra el Alcoholismo y otras Toxicomanías. En estas se señala que la "policía de narcóticos ha venido llevando a cabo la campaña contra el tráfico ilícito y uso indebido de drogas enervantes, preferentemente la destrucción de cultivos de adormidera y decomisos de la frontera, cooperando con las autoridades del ramo de los Estados Unidos Norteamericanos"..$^{90}$ En esas líneas se hace referencia a la primera campaña de erradicación, celebrada en la primavera de 1938, de la que tenemos constancia. Aquel año, fuerzas de la $4^{\circ}$ zona militar apoyaron a policías de narcóticos de la DSP en la destrucción de cultivos de amapola en el estado de Sonora. ${ }^{91} \mathrm{~A}$ los soldados y a cuatro policías sanitarios los acompañó el agente de la Oficina de Aduanas Alvin Scharff, quien calificó la cooperación entre ambas corporaciones

${ }^{88}$ AHSSA, SP, SJ, c. 28, exp. 6.

${ }^{89}$ AHSSA, SP, SJ, c. 28, exp. 9.

90 DSP, Memoria del Departamento de Salubridad.

${ }_{91}$ NARA, RG 170, c. 22, folder 3. 
de inédita pues se trató de "la primera vez que autoridades de salud y las fuerzas armadas cooperaban seriamente entre ellas en ese terreno". ${ }^{92}$ La dinámica se repitió por algunos años más. En 1940, por ejemplo, la campaña de erradicación estuvo constituida por dos policías antinarcóticos del DSP, cinco policías judiciales del estado de Sinaloa, un subteniente del $15^{\circ}$ Batallón de Ejército Mexicano, seis soldados y un agente aduanal de Estados Unidos. ${ }^{93}$ No tenían ni caballos, y los dueños de los pocos que había en la región no querían prestarlos al destacamento de soldados y policías. ${ }^{94}$ Pareció ya un gran logro que el DSP pudiera rentar una avioneta de reconocimiento para fotografiar desde el cielo la región. ${ }^{95}$

Campañas similares se repitieron a lo largo de los siguientes años. Sin embargo, como se demostrará a continuación, la participación de los agentes antinarcóticos del DSP fue disminuyendo en favor de los agentes de la Policía Judicial y del ejército mexicano.

En las memorias de la Secretaría de Salubridad y Asistencia de 1944 (en 1943 el Dsp se había convertido en la ssa) se les concede mínima importancia a las tareas antinarcóticos. Se subraya, si acaso, la participación de agentes de la Policía Federal de Narcóticos en las campañas de erradicación llevadas a cabo en los estados de Sinaloa, Durango, Chihuahua y Sonora, este último estado en que para 1944 "puede decirse que el problema [de la siembra de droga] está próximo a desaparecer, ya que el C. Gobernador del mismo, con especial empeño que es digno de mencionarse, ha combatido este tráfico ilegal de enervantes". ${ }^{96}$

\footnotetext{
92 Gray a Irey. En el original de Sharff citado en la carta de Carroll Gray: "This is the first time in the history of Mexico that the Public Health Service and the Army are seriously cooperating with each other in this matter [...]."

${ }^{93}$ NARA, RG 170, c. 22, folder 2.

94 NARA, RG 170, c. 22, folder 2.

${ }^{95}$ Véase NARA, RG 170, c. 22, folder 2.

96 SSA, Memoria 1944-1945.
} 
Otras dependencias, como la Secretaría de la Defensa $\mathrm{Na-}$ cional (SEDENA), cada vez ganaban más preponderancia en las campañas contra las drogas. Así, por ejemplo, entre septiembre de 1944 y agosto de 1945 se registró que el $12^{\circ}$ Batallón de Infantería participó "en la destrucción de grandes plantíos de amapola, con la que se intentaba propagar el vicio del opio". ${ }^{97}$ Por su parte, agentes de la Policía Judicial trabajaban a principios de 1944 con agentes de la Oficina de Aduanas de los Estados Unidos en Nuevo Laredo, Agua Prieta y Chihuahua. ${ }^{98}$

Durante marzo de 1946 la aeronave BHB-1509 de la Fuerza Aérea Mexicana realizó vuelos de observación y localización de campos de adormidera. Este avión iba tripulado por el agente del Departamento del Tesoro estadounidense Salvador Peña, el inspector de la Policía Federal de Narcóticos Gilberto Hernández Ferral, algunos militares, políticos, un camarógrafo y un mecánico. ${ }^{99}$ Sin embargo, en su Memoria Anual la ssa reconocía que durante 1946 había tenido una "reducidísima policía de Narcóticos". ${ }^{100}$

Si es posible hallar puntos de inflexión en procesos sociales, entonces 1947 es el año de quiebre. En aquel año se desarrolló la “Campaña Nacional contra los Enervantes", considerada como la más importante registrada hasta el momento. Estuvo enfocada en la "destrucción de las fuentes de producción de enervantes, plantíos de adormidera, de marihuana y el descubrimiento de laboratorios clandestinos de transformación del opio crudo extraído de las amapolas en sus derivados de sales alcaloides". ${ }^{101} \mathrm{La}$ campaña, así como la mayoría de las acciones antidrogas de ese año y del resto del sexenio alemanista quedaron bajo el mando

97 SEDENA, “Labor de cooperación del ejército", en Memoria 1944-1945, p. 152.

${ }_{98}$ NARA, RG 170, c. 22, folder 6.

99 AHSSA, Salubridad Pública, Servicio Jurídico, c. 8, exp. 6.

100 SEDENA, Memoria 1945-1946, p. 121.

101 PGR, Memoria, 1948, pp. 17-19. 
de la PGR. Quedaron supeditadas a ésta la Policía Federal de Narcóticos de la ssa, así como unidades del Ejército Nacional y de la Fuerza Aérea Mexicana, policías locales de los estados y policías judiciales, tanto de la federación como del Distrito Federal. ${ }^{102}$

Para la campaña de 1947, la función de los agentes de la Policía de Narcóticos se limitó a la vigilancia de la frontera norte del país, así como a impedir que los traficantes huyeran y se internaran en Estados Unidos. A partir de ese año, sin embargo, sus operaciones se subordinaron al mando de la PGR y de los agentes de la Policía Judicial Federal.

La Policía Judicial Federal había sido distribuida de la siguiente manera: tres grupos en Durango, tres en Sinaloa, uno en Sonora y uno en Chihuahua. Por su parte, la SEDENa proporcionó fuerzas para escoltar y proteger a los diversos grupos encargados de la destrucción de plantíos y de las aprehensiones. ${ }^{103}$ Además, un contingente de cinco avionetas de la Fuerza Aérea Mexicana colaboró en la localización de plantíos y campos clandestinos de aterrizaje, lanzamiento de impresos de propaganda para disuadir a los campesinos de sembrar plantas ilícitas, transporte de agentes federales y de tropas de auxilio, conducción de detenidos para ponerlos a disposición de las autoridades judiciales, abastecimiento de víveres, medicamentos, y toda clase de auxilios a los expedicionarios. ${ }^{104}$

En el libro de memorias del trienio 1947-1950 ya no se menciona la participación de agentes de la Policía Federal de Narcóticos en las campañas de erradicación de drogas. Solamente se subraya que la Oficina de Enervantes (en ese entonces en el Departamento de Control de Medicamentos de la ssa) mantuvo una "brillante colaboración con la Procuraduría General

102 PGR, Memoria, 1948 , p. 33.
103 PGR, Memoria, 1948 , p. 21.
104 PGR, Memoria, 1948 , p. 21. 
Imagen 3

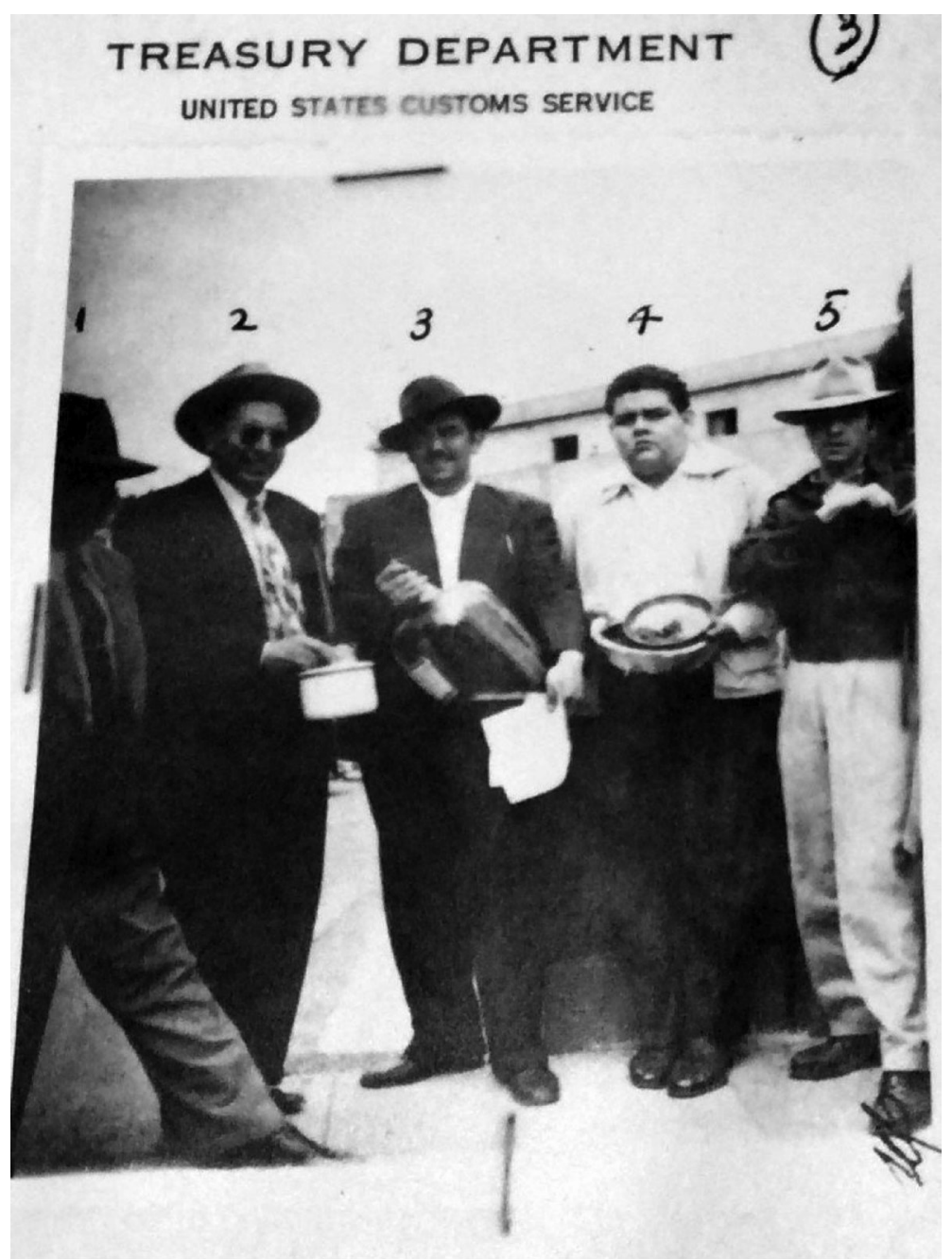

El agente Huerta de la Policía Federal de Narcóticos (número 1), otros funcionarios de la ssa y un informante (número 5) posan tras una redada en la ciudad de México. Fuente: NARA, RG 170, c. 23, folder 1. 
de la República en la localización y destrucción de plantíos muy numerosos y extensos, en diversas regiones del país". ${ }^{105}$ Más adelante, en una frase que deja ver el lugar secundario que comenzaba a tener la ssa en el plano del control antinarcóticos, se señala que "las felicitaciones que ha recibido la PGR, tanto de los sectores representativos nacionales, como de los organismos internacionales conectados directa o indirectamente con el problema de las drogas enervantes, también han alcanzado a la Secretaría de Salubridad y Asistencia y a esta dependencia". ${ }^{106}$ Esta frase deja ver un proceso que analizaremos en las últimas secciones de este artículo; a saber, el avance de la policía de la PGR en el campo antinarcóticos.

\section{LA POLICÍA DE NARCÓTICOS EN LAS DÉCADAS DE LOS AÑOS CUARENTA Y CINCUENTA}

En diciembre de 1940 se autorizó la formación del Cuerpo de Policía Sanitaria Federal. Se justificó su creación en virtud de que

[...] para obtener éxito en la campaña que contra el tráfico de drogas enervantes ha emprendido el Departamento de Salubridad, necesita éste contar con agentes policiacos que practiquen las delicadas investigaciones que se requieren, y persigan y aprehendan a los traficantes de drogas, a fin de que éstos sean consignados a las autoridades competentes para la imposición de las penas a que se han hecho acreedores. ${ }^{107}$

Asimismo, se especificó que eran necesarios policías “dotados de conocimientos y técnica”, así como "honradez y laboriosidad” para obtener resultados positivos. Se estableció que, de

105 SSA, Memoria 1947-1950, p. 182.

106 SSA, Memoria 1947-1950, p. 182.

107 DOF, “Acuerdo que autoriza la formación de un Cuerpo de Policía Sanitaria Federal” (31 diciembre 1940). 
acuerdo con el presupuesto del año próximo, el Dsp procedería a formar el cuerpo, "con el número de plazas que juzgue necesarias". 108

En octubre de 1943, el presidente de la República, Manuel Ávila Camacho, decretó la fusión del DSP con el Departamento de Asistencia Pública en una sola organización que pasó a llamarse Secretaría de Salubridad y Asistencia (ssA). ${ }^{109}$ La Oficina de Toxicomanías fue integrada a esta nueva institución. Asumió la dirección de la ssa el distinguido médico Gustavo Baz. Las cuestiones relacionadas al tema narcóticos quedaron ancladas a la Dirección General de Higiene de la Alimentación, ${ }^{110}$ y, específicamente, a la Oficina de Control de Enervantes, Sección de Toxicomanías.

Pocos meses antes de la creación de la ssA, en agosto de 1943 y ante la perspectiva de una reorganización del DSP, se había decretado la sustitución del Servicio de Narcóticos por una corporación llamada Policía Federal de Narcóticos (PFN). ${ }^{11}$ El mando de la PFN fue asumido por un coronel de apellido Guzmán quien tuvo 16 hombres a su mando. Ya desde la creación del grupo, se valoró la posibilidad de planear un programa de entrenamiento para la nueva organización. ${ }^{112}$

No tenemos estimaciones exactas de los elementos que constituían la corporación. Según una confesión hecha por Rafael Pascasio Gamboa, sucesor de Gustavo Baz al frente de la ssA, al representante de la Oficina de Aduanas de Estados Unidos en México, la PFN contaba hacia 1947 con unos 180 elementos. El

${ }_{108}$ DOF, “Acuerdo que autoriza la formación de un Cuerpo de Policía Sanitaria Federal" (31 diciembre 1940).

109 DOF, "Decreto que crea la Secretaría de Salubridad y Asistencia" (18 octubre 1943).

110 A partir de 1944 fue renombrada como Dirección General de Higiene de la Alimentación y Control de Medicamentos.

111 NARA, RG 170, c. 22, folder 5.

112 NARA, RG 170, c. 22, folder 5. 
número parece inverosímil y no coincide con otras cifras (véase infra). En esa misma conversación confesó que no confiaba en ninguno de sus agentes y que si alguno de ellos quería participar en las campañas de erradicación era con la única finalidad de maximizar sus posibilidades de obtener "mordidas". "Todos son corruptos”, sentenció. ${ }^{113}$

Los datos de Gamboa contrastan con los del químico David de la Rosa, jefe de la Dirección General de Medicamentos (DGHACM) de la ssa en 1946. Según De la Rosa, la PFN sólo contaba con dos inspectores: Rafael Huerta Nava y Gilberto Hernández Ferrara. Señaló que unos años atrás la ssa llegó a contar con hasta 30 agentes y que ignoraba los motivos por los que se habían suprimido estas plazas. Asimismo, De la Rosa mencionó que como esta policía era la que año tras año había participado en las campañas para destruir cultivos y capturar traficantes, representantes del gobierno estadounidense habían tenido especial interés en las actividades que desarrollaban estos agentes; afirmó también que el Departamento del Tesoro de Estados Unidos había proporcionado "datos de los traficantes y lugares exactos donde se encuentran sembrados los campos de adormidera y de manera extraoficial ha ayudado a erogar los gastos que se requieren en esta labor". ${ }^{114}$

En un tono menos optimista, De la Rosa manifestó que ni con la ayuda del gobierno estadounidense se habían logrado cubrir las necesidades de la Policía Federal Sanitaria para el combate a las drogas. Señaló que el sueldo que recibían los inspectores "en comparación con el trabajo que desarrollan y del peligro a que se ven expuestos es muy bajo”. Añadió que a pesar de ser tan solo "dos elementos especializados en el ramo de narcóticos [estos] han correspondido en forma eficaz al servicio que se le tiene recomendado". De la Rosa llamó a que,

113 NARA, RG 170, c. 23, folder 1.

114 AHSSA, SP, SJ, c. 10, exp. 5. 
conforme al Código Sanitario, se respetara la competencia de la ssa como el principal agente del Estado encargado de combatir el tráfico de enervantes. Otras secretarías y las autoridades locales, escribió, debían proporcionar su cooperación. ${ }^{115}$ En 1947 se incluyó en el plan de trabajo de la DGHACM la necesidad de por lo menos diez inspectores para "evitar por todos los medios que la ley señala, el tráfico ilícito de enervantes". ${ }^{116} \mathrm{El}$ plan no parece haberse llevado a cabo y el declive de la Policía Sanitaria no se detuvo.

La información de De la Rosa coincide parcialmente con el informe que escribiera en febrero de 1947 el representante del Departamento del Tesoro en ciudad de México a su jefe en Estados Unidos acerca de la configuración del programa antinarcóticos en México. En ese documento denuncia que si bien por mucho tiempo hubo una guerra burocrática entre la PGR y el ssa respecto del monopolio de la política antidrogas, para 1947 se había llegado al entendimiento de que "los asuntos antinarcóticos estarían bajo el control absoluto de la PGR; los agentes sanitarios actuarían bajo sus órdenes". Así se lo hicieron saber "con lenguaje claro e inequívoco" tanto el procurador general de la República como el doctor Gamboa. Sin embargo, "el acuerdo no podía ponerse por escrito para no poner al ssa bajo presión”. ${ }^{117}$

Además de la subordinación hacia la Policía Judicial, la PFN tuvo que hacer frente a la recién creada Dirección Federal de Seguridad (DFS), institución motivada por los intentos de Miguel Alemán de centralizar el poder. Como ya se ha estudiado, la DFS, además de combatir la disidencia y la oposición al gobierno, ${ }^{118}$ intervino en políticas de drogas con fines - por decir lo

\footnotetext{
115 AHSSA, SP, SJ, c. 10, exp. 5.

116 AHSSA, SP, SJ, c. 21, exp. 9.

117 NARA, RG 170, c. 23, folder 1.

118 SERvín, “El delator, una figura cotidiana”, pp. 144-156.
} 
menos- ajenos al interés público. ${ }^{119}$ Por si no fuera suficiente, en noviembre de 1947 se publicó la modificación a los artículos 193, 194 y 197 del Código Penal. Con la reforma se duplicó el tiempo de sanción carcelaria y se incrementaron las multas económicas en relación con las tipificadas en el Código Penal de 1931. Además, se incluyó el delito de "proselitismo en materia de enervantes” y se amplió la gama de sustancias controladas en conformidad con los convenios internacionales suscritos por México. ${ }^{120}$ Este nuevo ambiente de securitización del combate al tráfico de drogas afectó la sostenibilidad de la Policía de Narcóticos de la ssA.

El 16 de julio de 1950, por acuerdo presidencial, se “constituye" la Policía Federal de Narcóticos. No se trata, como ya vimos, de una creación, pues un grupo de elementos dentro de la ssa ya llevaba desde 1943 las siglas de la PFN. En cualquier caso, el Acuerdo Presidencial de 1950 sí supone la reorganización total del grupo y un nuevo inicio. Fue integrada por un jefe, un subjefe, cuatro jefes de grupo y once agentes, “en su mayoría Oficiales del Ejército”. ${ }^{121}$ En otra versión, a la PFN la constituyeron "un director, un jefe de control, tres jefes de grupo, catorce agentes y trabajadores administrativos". ${ }^{122}$ En las Memorias de la ssa para el periodo 1952-1958 se subraya que la creación de la PFN tuvo como objetivo principal "cumplir con las estimaciones de los tratados internacionales y salvaguardar los intereses y la tranquilidad del pueblo mexicano". ${ }^{123}$

119 Como bien ha señalado Sergio Aguayo, no se conoce una fecha exacta de la creación de la DFs. El primer documento oficial que habla de esta organización data de marzo de 1947. Véase Aguayo, La Charola, p. 62. Sobre el espíritu centralizador de la DFS, véase Navarro, Political Intelligence, p. 150.

120 DOF, “Decreto que reforma y adiciona los artículos 193, 194 y 197 del Código Penal para el Distrito y Territorios Federales en materia del Fuero Común y para toda la República en materia del Fuero Federal” (14 noviembre 1947).

121 AHSSA, SP, SJ, c. 70, exp. 5.

122 SSA, Memoria 1952-1958, p. 30.

123 SSA, Memoria 1952-1958, p. 30 
Los informes oficiales muestran que durante la década de 1950 la Policía Federal de Narcóticos de la ssa continuó participando en las campañas contra los enervantes. Por ejemplo, entre septiembre de 1951 y agosto de 1952 esta corporación consignó para su detención preventiva a 87 hombres y 28 mujeres por el delito de tráfico de enervantes. ${ }^{124}$

Hacia 1952 el jefe de la PFN era el coronel Joaquín Solano Chagoya. Durante su periodo al frente de la organización propuso un plan de reorganización según el cual la PFN iba a limitar sus funciones a la vigilancia de los puertos marítimos y fronterizos del país. En el plan enviado al jefe de la ssa se proponía el siguiente cuadro jerárquico: un jefe, un subjefe, un abogado consultor, un médico, un químico laboratorista, cinco jefes de grupo y 35 agentes. Además, se contemplaba contar con un laboratorio químico, un gabinete antropométrico y cinco vehículos. Los agentes se distribuirían en diferentes células compuestas por cinco agentes y un jefe de grupo en las siguientes regiones: Tijuana y Mexicali; Laredo y Matamoros; Tampico y Veracruz; Acapulco y Nogales. Según el plan, los agentes serían relevados periódicamente para "evitar que se hagan demasiado conocidos o adquieran compromisos amistosos o sociales que entorpezcan su labor". ${ }^{125}$ Se arreglaría una dotación de armamento y municiones, así como la posible cesión de militares con la SEDENA. Lo último significaría "una gran ventaja" no solo porque la SEDENA continuaría pagando su sueldo sino por "su espíritu de disciplina y trabajo, así como las normas de moral en que están acostumbrados a actuar [lo cual] los pone a salvo de caer en el soborno". ${ }^{126}$ No es claro si esta reorganización sucedió. Es probable que no porque a finales de 1953 Solano Chagoya fue reemplazado por Humberto

124 AHSSA, SP, SJ, c. 36, exp. 14.

125 AHSSA, SP, SJ, c. 36, exp. 14.

126 AHSSA, SP, SJ, c. 36, exp. 14. 
Mariel Lazo, personaje al que se vinculó con Dolores Estévez Zuleta y su red de tráfico de drogas. Además, sabemos que los agentes de la PFN continuaron realizando detenciones y decomisos más allá de puertos marítimos y fronterizos. Los informes de captura de presuntos traficantes redactados por los jefes de grupo de la organización, así como los informes de actividades que trimestralmente presentaba el jefe de la Policía, dan cuenta de la significante presencia de los agentes de la PFN en todo el país. Su condición de ente coadyuvante de la PGR le daba capacidad para hacer investigaciones en toda la federación. En todos los casos, su obligación era presentar tanto la evidencia recolectada como a los detenidos ante el Ministerio Público correspondiente o a la Dirección General de Averiguaciones Previas en el Distrito Federal.

Entre 1952 y 1953, agentes de la PFN participaron en arrestos ocurridos en Sinaloa, Nuevo León, Tamaulipas, Guanajuato, Distrito Federal, Campeche, Baja California y Estado de México. De ese periodo sobresalen el desmantelamiento de un laboratorio de heroína "de la mejor calidad" en el oriente del Distrito Federal, ${ }^{127}$ la muerte en un tiroteo de uno de los jefes de grupo de la corporación, el teniente de caballería Salvador Apam Ruiz, ${ }^{128}$ y la captura en Tijuana de Gonzalo Beltrán León, uno de los principales exportadores de heroína a Los Ángeles. ${ }^{129}$ El opio crudo, seguido por la marihuana, continuaba siendo la sustancia que más se decomisaba. En algunos casos, operativos policiacos involucraban la captura de hasta 30 kilos de opio. Destaca la presencia de no menos de diez mujeres arrestadas en este periodo, algunas de ellas acusadas por consumo y otras por tráfico de enervantes. ${ }^{130}$ Durante los primeros seis meses de 1954 los agentes de la PFN participaron solamente

\footnotetext{
127 AHSSA, SP, SJ, c. 70, exp. 5.

128 AHSSA, SP, SJ, c. 70, exp. 5.

129 AHSSA, SP, SJ, c. 70, exp. 5.

130 AHSSA, SP, SJ, c. 70, exp. 5.
} 
en 14 actividades antinarcóticos, en su mayoría detenciones o confiscaciones muy menores. ${ }^{131}$

Ciertamente las víctimas de la mayoría de los arrestos o decomisos hechos por la PFN eran pequeños traficantes de opio o marihuana y, en algunos casos, simples consumidores. Los ejemplos abundan: vendedores de hierba en colonias populares del Distrito Federal, transportistas de bultos de marihuana con dirección a "picaderos" en el centro de la ciudad, forjadores de carrujos, individuos sorprendidos con "residuos de marihuana en el bolsillo cuando pretendían robar" u "ostentando en los brazos huellas de piquetes de agujas hipodérmicas”. ${ }^{132}$ Los culpables son siempre los pobres de la ciudad. Son pocos los casos de decomisos o arrestos que involucran bandas más o menos bien organizadas y con redes en Estados Unidos o en terceros países. Con todo, hubo dos excepciones significativas.

La primera es la detención en marzo de 1954 de una red de traficantes de marihuana compuesta por "Willie Morales, Victor Ruanova y Louis Van Jones”. ${ }^{133} \mathrm{El}$ modus operandi era el siguiente: algún miembro de la banda compraba la droga en algún punto de México; manejaba hasta Matamoros, Tamaulipas, ciudad en la que cambiaba las placas mexicanas del coche por unas estadounidenses; en ese punto, otro miembro de la banda asumía la conducción del auto, cruzaba la frontera y se dirigía hasta Nueva York, donde se vendía la droga. Gracias a la investigación de la PFN en la que parecen no haberse involucrado las autoridades estadounidenses se consignaron 500 kilos de marihuana, más de 5000 dólares y tres automóviles. ${ }^{134}$ En marzo de 1955 Morales finalmente fue detenido "por la policía de los E.U.A.” por datos supuestamente proporcionados por la PFN. Además, según el informe anual de esta corporación, se "logró

131 AHSSA, SP, SJ, c. 70, exp. 5.

132 AHSSA, SP, SJ, c. 70, exp. 5.

133 AHSSA, SP, SJ, c. 70, exp. 5.

134 AHSSA, SP, SJ, c. 70, exp. 5. 
el decomiso de 1000 gramos de cocaína, que se encontraba en la caja de seguridad de un Banco" en la Ciudad de México. ${ }^{135}$

También en marzo de 1955 agentes de la PFN capturaron al presunto traficante Antoine D'Agostino Scarfoni, ciudadano francés con antecedentes criminales en Argelia y Francia desde 1935. D'Agostino fue arrestado junto con otros dos ciudadanos extranjeros. ${ }^{136} \mathrm{La}$ acusación contra D’Agostino no prosperó porque fue arrestado tres años después, nuevamente en Canadá, país en el que fue puesto preso hasta principios de los años sesenta. ${ }^{137}$ Ese mismo mes de marzo de 1955 agentes de la PFN capturaron en Mexicali a "los traficantes de opio y marihuana" Fidel Carrillo Elenes, Fidel Carrillo Caro y Ernesto Fonseca Carrillo, "a quienes se les recogieron dos armas largas y tres pistolas, regular cantidad de cartuchos, tres cajas de cartón con marihuana y nueve latas conteniendo opio". 138

Las operaciones fueron posibles por la aparente buena relación que todavía tenía la PFN con el Departamento del Tesoro de los Estados Unidos, en la década de 1950 la instancia encargada de la cooperación antinarcóticos entre ambos países. Así, por ejemplo, en 1953 Benjamin S. White, representante de la Oficina del Tesoro en ciudad de México, así como agentes del Federal Bureau of Narcotics, participaron junto con agentes de la PFN en la detención del presunto narcotraficante Enrique Treviño, ${ }^{139}$ perseguido e investigado sin suerte por los estadounidenses desde hacía ya varios meses. ${ }^{140}$

\footnotetext{
135 AHSSA, SP, SJ, c. 107, exp. 3.

136 AHSSA, SP, SJ, c. 70, exp. 5.

137 Committee on Government Operations. Senate Permanent Subcommittee on Investigations, "Organized Crime and Illicit Traffic in Narcotics, Part 4 (Hearings Published)” (30 julio de 1964), 1004, HRG-1964-OPS-0007, Congressional Publications.

138 AHSSA, SP, SJ, c. 70, exp. 5.

139 AHSSA, SP, SJ, c. 70, exp. 5.

140 NARA, RG 170, c. 161, folder 2.
} 
Ese mismo año, el Departamento del Tesoro, por medio de Benjamin S. White, hizo extensiva la invitación al jefe de la PFN, Humberto Mariel Lazo, para comenzar un programa de entrenamiento para los miembros de la PFN pagado por ambos países. La falta de respuesta se interpretó como resultado de los límites presupuestarios de su organización y de su propio capricho, según el cual Estados Unidos "cual hermano mayor" debía pagar los gastos enteramente ("Further, Sr. Mariel takes the attitude that the United States Government is the big brother in such matters and should bear all expenses"). ${ }^{141}$

\section{EL DECLIVE Y FIN DE LA POLICÍA ANTINARCÓTICOS DE}

\section{LA SECRETARÍA DE SALUBRIDAD Y ASISTENCIA}

No es claro el fin de la PFN. En las memorias de la SsA correspondientes al periodo 1954-1960 se admite que el "control sobre drogas estupefacientes" y la "vigilancia sobre el tráfico de narcóticos" pasó a cargo de la PGR. ${ }^{142}$ Para ello no se especifican fechas, aunque, como ya hemos visto, esta transición ocurrió desde finales de la década de los cuarenta. Con todo, las memorias de la SSA, así como otros reportes internos de esa institución, dejan ver que hasta finales de la decada de los años cincuenta, agentes de este cuerpo policiaco continuaron colaborando en la detención de consumidores, productores y traficantes de sustancias ilícitas. ${ }^{143}$

Según un informe del representante de la Oficina del Tesoro de los Estados Unidos en México, la PFN estaba constituida en 1959 solamente por diez agentes residentes en la ciudad de México y un viejo Ford. Según este documento, el sueldo de un policía de la PFN era de 800 pesos mientras el de cada agente de

141 NARA, RG 170, c. 161, folder 4.

142 SSA, Memoria 19458-1964, p. 157.

143 Por ejemplo: «Memoria del ejercicio de la Dirección de Control de Medicamentos», AHSSA, SP, SJ, c. 70, exp. 5. 
la PJF rebasaba los 1200 pesos. ${ }^{144}$ En el mismo informe el funcionario deja ver su confusión entre las facultades de la PFN y de la PGR. Aunque la realidad era más compleja, se contentaba con entender que la PFN tenía jurisdicción sobre delitos del Código de Salud y la PJF sobre el Código Penal. ${ }^{145}$

En todo caso, las cifras de la Oficina del Tesoro eran precisas pues entre febrero de 1959 y diciembre de 1960 el comandante Enrique Soto Rodríguez ocupó el cargo de jefe de la Policía Federal de Narcóticos. Se reportó, en efecto, que tendría diez agentes al mando. Durante los primeros diez meses de su gestión se logró la consignación de por lo menos 90 personas acusadas por delitos contra la salud, la destrucción de muchas hectáreas de marihuana en el centro del país y el decomiso de varias toneladas de la misma hierba, la mayoría en la ciudad de México, Baja California Norte, Nuevo León, Morelos, Estado de México, Durango, Zacatecas y San Luis Potosí. ${ }^{146}$

Da cuenta del reducido número de agentes de la PFN que el propio comandante Enrique Soto participase personalmente en la destrucción de cultivos ilícitos en zonas serranas del norte del país. Según su propio reporte, a finales de julio de 1959 se encontraba en los municipios de Galeana y Rayones del estado de Nuevo León, en donde después de "una semana de recorrido en “jip [sic], a caballo y a pie”, él y su cuadrilla encontraron varios plantíos de cannabis, los cuales fueron destruidos. Además, detuvieron a uno de los ejidatarios del lugar, mismo que fue puesto a disposición del Ministerio Público de Monterrey. ${ }^{147}$

De entre las decenas de detenidos por la PFN destacó la aprehensión de dos ciudadanos estadounidenses: Manuel E. Acevedo, un supuesto traficante que enviaba marihuana de México

\footnotetext{
144 NARA, RG 170, c. 161, folder 4.

145 NARA, RG 170, c. 160, folder 1.

146 AGN, SSA, SP, c. 920, exp. 3.

147 AGN, $S S A, S P$, c. 920, exp. 3.
} 
hasta Miami, Florida, y el poeta beatnick Philip Lamantia. ${ }^{148}$ La aprehensión la llevaron a cabo los agentes 5 y 8 de la PFN el 28 de abril de 1959 a las 13:00 horas en avenida Juárez. Según el informe firmado por el comandante Soto, a los acusados se les decomisó "marihuana ya preparada para fumar en una cajetilla metálica para cigarros". Lamantia, quien entrega "una bolsa con más o menos medio kilo de semilla de y deshechos de marihuana, nueve cajetillas de cerillos llenas de colillas de la misma yerba y otro pomo chico con una cantidad de hierba molida", aceptó ser aficionado al opio, la heroína y la marihuana desde hacía diez años. ${ }^{149}$

Ese mismo año Lamantia había publicado el libelo Narcotica, en el que demandaba la extinción de las leyes prohibicionistas de drogas. "I say abolish the prohibition of the sacred narcoticsstop the sensationalism!". ${ }^{150}$ Tres años después el poeta regresaría a México y volvería a ser expulsado al acusársele de posesión de drogas. ${ }^{151}$ Fue a partir de esa experiencia que se tomó la decisión de que casos que involucraran delitos contra la salud por parte de extranjeros "independientemente de la consignación a la PGR, serán comunicados por esta policía [la PFN] al Departamento de Inspección Migratoria de la Secretaría de Gobernación $[\ldots]$ aun cuando no se les sorprenda infraganti". ${ }^{152}$

Para septiembre de 1959 el comandante Soto le pidió al secretario de la SSA un aumento de presupuesto para los sueldos del personal de la PFN y así "garantizar la máxima eficiencia y honestidad en la misión que nos tiene encomendada". Además, solicitó la compra de: " 4 vehiculos en perfectas condiciones, 4 armas largas calibre 30, 4 lanzallamas portátiles, 4 máscaras antigas y

${ }^{148}$ En relación a la estadía, detención y posterior expulsión de México de Philip Lamantia véase ARIDJIs, "Philip Lamantia: el poeta”, pp. 71-75.

149 AGN, SSA, SP, c. 920, exp. 3.

150 Lamantia, Narcotica.

151 ArIdjIs, "Philip Lamantia: el poeta".

152 AGN, SSA, SP, c. 920, exp. 3. 
4 equipos de los usados por la campaña antipaludismo". ${ }^{153} \mathrm{No}$ hemos encontrado evidencias de que esta solicitud haya sido respondida. Más aún: incluso la documentación disponible indica que el declive de este cuerpo policíaco era cada vez más evidente.

Prueba de ello es que en diciembre de 1959 un agente antinarcóticos de Estados Unidos se sorprendió al enterarse de la existencia de la PFN. Al inquirir al subjefe de la PJF, el coronel Héctor Hernández Tello, por el aparato policial antinarcóticos en la SsA, éste le respondió: "no es una organización en la que se pueda confiar; aceptan dinero de traficantes y no hacen casos judiciales". ${ }^{154}$ Para entonces, era precisamente Hernández Tello el encargado de discutir diariamente con los estadounidenses todo lo respectivo a la política antidrogas de México. ${ }^{155}$ La existencia de la PFN era ya casi sólo simbólica y aislada por completo de la cooperación internacional. Su papel se limitaba a subordinarse a la PJF.

La PFN pervivió algún tiempo más. En julio, agosto y septiembre de 1960, agentes del PFN al mando del capitán Enrique Soto Rodríguez, y “auxiliados por personal” del $7^{\circ}$ y $15^{\circ}$ Regimiento de Caballería del Ejército, "localizaron y destruyeron 31 plantíos de marihuana” en Morelos y Guanajuato. En total se reportó la "destrucción de 24740 kilogramos de marihuana verde y seca”. ${ }^{156}$ Para 1963 la PFN participó en las operaciones "Popocatepetl” y "Guanajuato" contra la siembra de marihuana. ${ }^{157}$ Ese mismo año la ssa realizó un proyecto de reestructuración de esta corporación. Se planteó que la PFN seguiría dependiendo de la ssa y que sus gastos burocráticos se cubrirían a partir de la recolección de multas. Asimismo, estaría constituida por los "agentes adscritos a esta misma secretaría,

\footnotetext{
153 AGN, SSA, SP, c. 920, exp. 3.

154 NARA, RG 170, c. 161, folder 4.

155 NARA, RG 170, c. 161, folder 5.

156 AHSSA, SSA, SP, c. 70, exp. 5.

157 NARA, RG 170, c. 161, folder 5.
} 
encargados de la vigilancia y cumplimiento de las disposiciones contenidas en el Código Sanitario y sus reglamentos". ${ }^{158}$ En este nuevo proyecto no se aludió más a la vigilancia o investigación relacionadas con drogas.

\section{CONCLUSIÓN}

El objetivo de este artículo fue el de rastrear la emergencia, ascenso y declive del aparato policial encargado del control de drogas dentro del Departamento de Salubridad Pública -después Secretaría de Salubridad y Asistencia- entre 1917 y principios de la década de 1960. Con ese fin, se utilizaron, entre otros, los archivos de la Policía de Narcóticos ubicados en el Archivo Histórico de la Secretaría de Salud (AHSSA).

El artículo presentó evidencia para señalar que la Policía de Narcóticos adscrita a las instituciones de salud nunca tuvo claridad legal ni jurídica en cuanto a sus límites y alcances. Sus agentes ejercieron facultades persecutorias y sancionadoras que llevaron a disputas con agentes del Ministerio Público, policías judiciales y otros agentes de corporaciones policiacas locales. La debilidad institucional y jurídica de la corporación la hizo incapaz de responder a las presiones que desde Estados Unidos exigían un servicio profesional y dedicado enteramente a las tareas antinarcóticos. Su adscripción a una institución de salud le hacía anacrónica ante un contexto internacional que comenzaba a percibir el problema de las drogas desde el paradigma de la seguridad. Su pérdida de relevancia relativa en favor de la PGR a partir del ecuador de la década de los años cuarenta y desaparición a principios de los años sesenta es resultado de esta tensión. Con todo, el desplazamiento de un régimen de tolerancia a uno prohibicionista no excluyó del todo a las autoridades de salud quienes, incluso hoy en día, continúan ejerciendo un papel preponderante en las

158 AGN, SSA, SP, c. 918, exp. 1. 
instituciones supranacionales abocadas a regular la producción, comercialización y consumo de ciertas sustancias.

El artículo contribuye al estudio de una corporación que ha recibido poca o nula atención por parte de la bibliografía académica. Sin embargo, es preciso señalar que de ninguna manera presenta resultados concluyentes en cuanto a la organización de las estructuras policiacas antinarcóticos en el sector salud en México. Más aún, no alcanza a establecer con claridad el fin de la PFN ni a examinar integralmente las prácticas de los agentes de la corporación para todo el periodo de estudio. Los vacíos en los reportes anuales del DSP $-\mathrm{y}$ posteriormente de la SSA-, así como la falta de expedientes disponibles de sus miembros para el periodo que va de la década de 1930 en adelante son solo algunos de los elementos que nos impiden tener un panorama más claro de la organización de la Policía de Narcóticos.

Nuevas investigaciones no solo podrán contrastar nuestras conclusiones en lo que se refiere al ascenso y declive de la Policía de Narcóticos adscrita a instituciones de salud. Se hace urgente una agenda de investigación que examine la relación de esta institución con el resto del campo de organizaciones involucradas en tareas antinarcóticos, incluyendo la Dirección Federal de Seguridad, la Policía Judicial Federal, así como policías estatales y locales. Consideramos que en el examen de las disputas burocráticas asociadas a la agenda antinarcóticos están muchas de las claves que explican los fracasos de reforma policial intentados en las últimas décadas, así como la falta de efectividad en la respuesta estatal contra la violencia resultante del tráfico de estupefacientes.

\section{SIGLAS Y REFERENCIAS}

AGN Archivo General de la Nación, Ciudad de México, México. AGN, SEGOB, DGIPS Archivo General de la Nación, fondo Secretaría de Gobernación, Dirección General de Investigaciones Politicas y Sociales, Ciudad de México, México. 
AGN, SSA, SP Archivo General de la Nación, fondo Salubridad y Asistencia, Secretaría Particular, Ciudad de México, México.

AHSSA, SP, SJ Archivo Histórico de la Secretaría de Salud, fondo Salubridad Pública, sección Servicio Jurídico, Ciudad de México, México.

AHSSA, SP, EP Archivo Histórico de la Secretaría de Salud y Asistencia, fondo Salubridad Pública, sección Expedientes Personales, Ciudad de México, México.

DOF Diaro Oficial de la Federación

DSP Departamento de Salubridad Pública

NARA, RG National Archives and Records Administration, Record Group, Maryland, Estados Unidos.

PGR Procuraduría General de la República

SSA Secretaría de Salubridad y Asistencia

SEDENA Secretaría de la Defensa Nacional

Aguayo Quezada, Sergio, La charola: una historia de los servicios de inteligencia de México, México, Grijalbo, 2001.

Aridjis, Homero, "Philip Lamantia: el poeta beatífico", en Revista de la Universidad de México, 90 (2011), pp. 71-75.

Astorga, Luis, Drogas sin fronteras, México, Grijalbo, 2003.

Astorga, Luis, "Traficantes de drogas, políticos y policías en el siglo xx mexicano", en Lomnitz (ed.), 2000, pp. 167-193.

Bernal, Rafael, El complot mongol, México, Libros del Asteroide, 2013.

Boyce, Geoffrey A., Jeffrey M. Banister y Jeremy Slack, "You and What Army? Violence, the State, and Mexico's War on Drugs", en Territory, Politics, Governance, 3: 4 (2015), pp. 446-468.

Campos, Isaac, "Degeneration and the Origins of Mexico's War on Drugs", en Mexican Studies/Estudios Mexicanos, 26: 2 (2010), pp. 379-408.

Campos, Isaac, Home Grown: Marijuana and the Origins of Mexico's War on Drugs, Chapel Hill, The University of North Carolina Press, 2012.

Chang, Jason Oliver, Chino: Anti-Chinese Racism in Mexico, 1880-1940, Illinois, The University of Illinois Press, 2017.

Contró, Aldo Francisco, Héctor Anaya y Carlos Zamudio, "La policía de salubridad en la ciudad de México. El caso de la división antinarcóticos 
1920-1934", México, Escuela Nacional de Antropología e Historia (2014), pp. 288-304.

Dávalos, Marcela, Regina Hernández Franyuti y Diego Pulido Esteva (eds.), Orden, policía y seguridad: historia de las ciudades, México, Instituto Nacional de Antropología e Historia, 2018.

Departamento de Salubridad Pública, Memoria de los trabajos realizados por el Departamento de Salubridad Pública, 1925-1928, vol. II, México, Editorial Cultura, 1928.

Departamento de Salubridad Pública, Memoria de las labores realizadas durante 1934 a 1935, México, Departamento de Salubridad Pública, 1935.

Departamento de Salubridad Pública, Memoria del Departamento de Salubridad Pública, septiembre de 1937-agosto de 1938, México, DSP, 1938.

Dussel Peters, Enrique, 40 años de la relación entre México y China, México, Universidad Nacional Autónoma de México, 2012.

EncIso, Froylán, Nuestra historia narcótica. Pasajes para (re)legalizar las drogas en México, México, Debate, 2015.

Galeano, Diego y Greogorio Kaminsky (eds.), Mirada (de) uniforme. Historia y crítica de la razón policial, Buenos Aires, Teseo, Universidad Nacional de Río Negro, 2011.

Gómez Izquierdo, José, "La hostilidad racista de México contra el ser chino”, en Dussel Peters, 2012, pp. 401-410.

GonzÁlez Oropeza, Manuel, “Policía y Constitución”, en Anuario Jurídico, Xv (1988), pp. 141-168.

Gootenberg, Paul, "Talking about the Flow: Drugs, Borders, and the Discourse of Drug Control”, en Cultural Critique, 71 (2009), pp. 13-46.

Gudiño-Cejudo, María Rosa, Laura Magaña-Valladares y Mauricio HerNÁndez Ávila, "La Escuela de Salud Pública de México: su fundación y primera época, 1922-1945”, en Salud Pública de México, 55: 1 (2013), pp. 81-91.

Lamantia, Philip, Narcotica, San Francisco, The Auerhahn Press, 1959. 
Lomnitz, Claudio (ed.), Vicios públicos, virtudes privadas: la corrupción en México, México, Centro de Investigaciones y Estudios Superiores en Antropología Social, 2000.

Navarro, Aaron William, Political Intelligence and the Creation of Modern Mexico, 1938-1954, Pennsylvania, University Park, Pennsylvania State University Press, 2010.

Olvera Hernández, Nidia Andrea, "Policías, toxicómanos y traficantes: control de drogas en la ciudad de México (1920-1943)”, tesis de maestría en antropología social, México, Centro de Investigaciones y Estudios Superiores en Antropología Social, 2016.

Palma Alvarado, Daniel (ed.), Delincuentes, policías y justicias: América Latina, siglos XIX y XX, Santiago, Chile, Universidad Alberto Hurtado, 2015.

Pérez Montfort, Ricardo, Tolerancia y probibición: aproximaciones a la bistoria social y cultural de las drogas en México (1840-1940), México, Debate, 2016.

Pérez MontFort, Ricardo, Yerba, goma y polvo: drogas, ambientes y policías en México, 1900-1940, México, Era, 1999.

Pérez Ricart, Carlos A., "El papel de la DeA en la emergencia del campo policial antidrogas en América Latina”, en Foro Internacional, LVIII: 1 (2018), pp. 5-48.

Piccato, Pablo, A History of Infamy: Crime, Truth, and Justice in Mexico, California, University of California Press, 2017.

Piccato, Pablo, City of Suspects. Crime in Mexico City, 1900-1931, Durham, Duke University Press, 2001.

Procuraduría General de la República, Memoria de la Procuraduría General de la República 1948, México, 1948.

Pulido Esteva, Diego, "El caso Quintana: policías, periodistas y hampones en la capital mexicana de los años veinte", en Palma Alvarado (ed.), 2015.

Pulido Esteva, Diego, "Gendarmes, inspectores y comisarios: historia del sistema policial en la ciudad de México, 1870-1930”, Ler História, 70 (2017), pp. 37-58. 
Pulido Esteva, Diego, "Policía: del buen gobierno a la seguridad, 17501850”, en Historia Mexicana, LX: 3 (239) (ene.-mar. 2011), pp. 1595-1642.

Pulido Esteva, Diego, “Trabajo, clase y prácticas policiales en las comisarías de la Ciudad de México, 1870-1920”, en Historia Mexicana, LXviII: 2 (270) (oct.-dic. 2018), pp. 667-712.

Ross, Paul, "From Sanitary Police to Sanitary Dictatorship”, tesis de doctorado, Chicago, University of Chicago, 2005.

Salazar, Dalia, y Begoña Hernández, "Introducción”, en Guía del Fondo de la Secretaría de Gobernación, México, Instituto Nacional de Antropología e Historia, Instituto Nacional de Estudios Históricos sobre la Revolución Mexicana, 2006.

Schievenini, José Domingo, "La criminalización del consumo de marihuana en México (1912-1961)", tesis de doctorado, México, Universidad Nacional Autónoma de México, 2018.

Schievenini, José Domingo, "La prohibición de las drogas en México (19121929)", en Revista Latinoamericana de Seguridad Ciudadana, 13 (2013), pp. 57-68.

Secretaría de la Defensa Nacional, Memoria de la Sedena 1944-1945, México, 1945.

Secretaría de la Defensa Nacional, Memoria de la Sedena 1945-1946, México, 1946.

Secretaría de Salubridad y Asistencia, Memoria 1944-1945, México, ssa, 1945.

Secretaría de Salubridad y Asistencia, Memoria 1947-1950, México, SSA, 1951.

Secretaría de Salubridad y Asistencia, Memoria 1952-1958, México, ssa, 1959.

Secretaría de Salubridad y Asistencia, Memoria 1958-1964, México, SSA, 1965.

SERvín, Elisa, "El delator, una figura cotidiana del alemanismo priista", en $A n$ tropología. Boletin Oficial del Instituto Nacional de Antropología e Historia, (2016), pp. 144-156. 
Sмiтн, Benjamin T., "The Rise and Fall of Narcopopulism: Drugs, Politics, and Society in Sinaloa, 1930-1980", en Journal for the Study of Radicalism, 7: 2 (2013), pp. 125-165.

Speckman, Elisa, "En la inmensa urbe y el laberinto de los archivos: la identificación de criminales en la ciudad de México", en GalEano y Kaminsky (eds.), 2011, pp. 111-152.

Yankelevich, Pablo, “Extranjeros indeseables en México (1911-1940). Una aproximación cuantitativa a la aplicación del artículo 33 constitucional”, en Historia Mexicana, LIII: 3 (211) (ene.-mar. 2004), pp. 693-744. 
